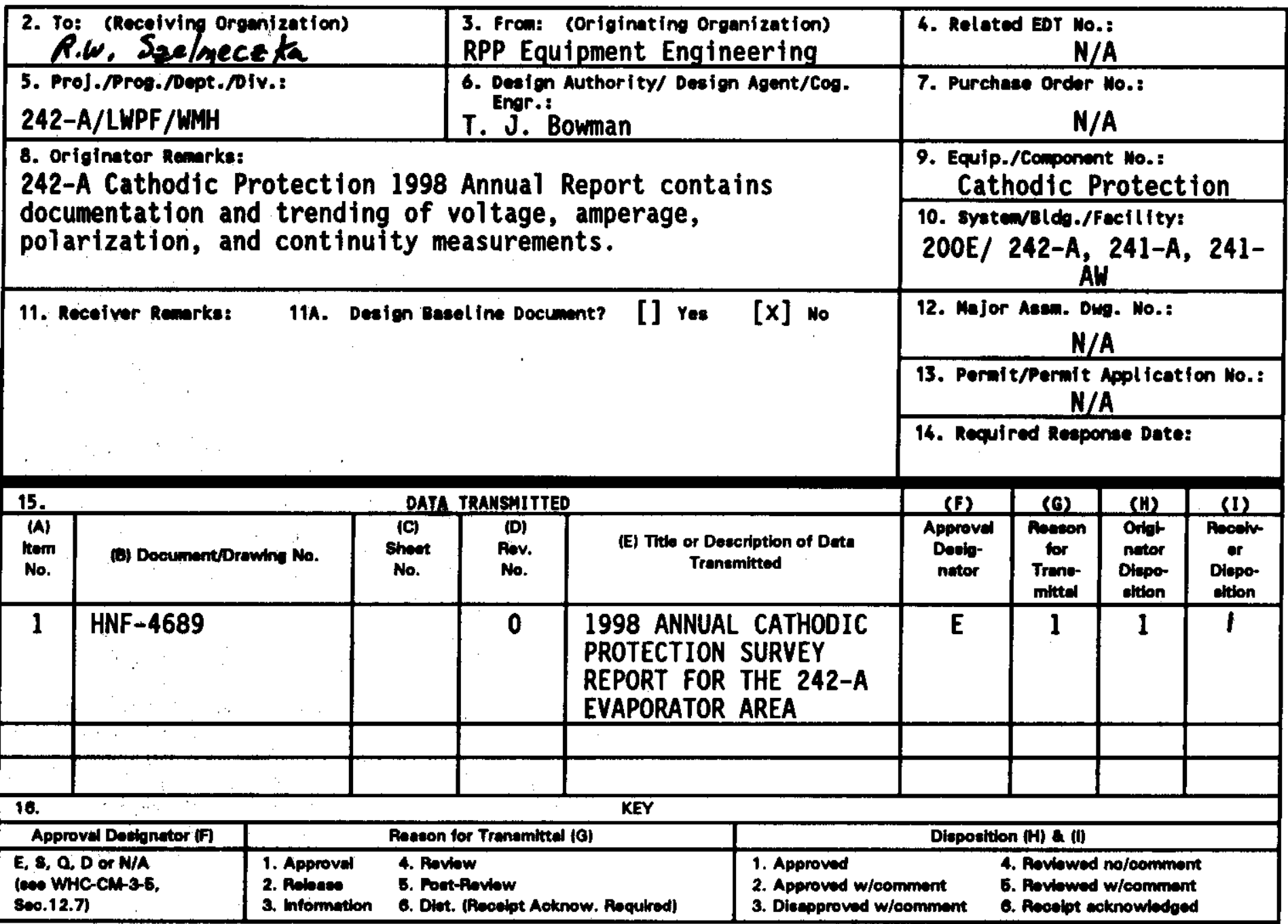

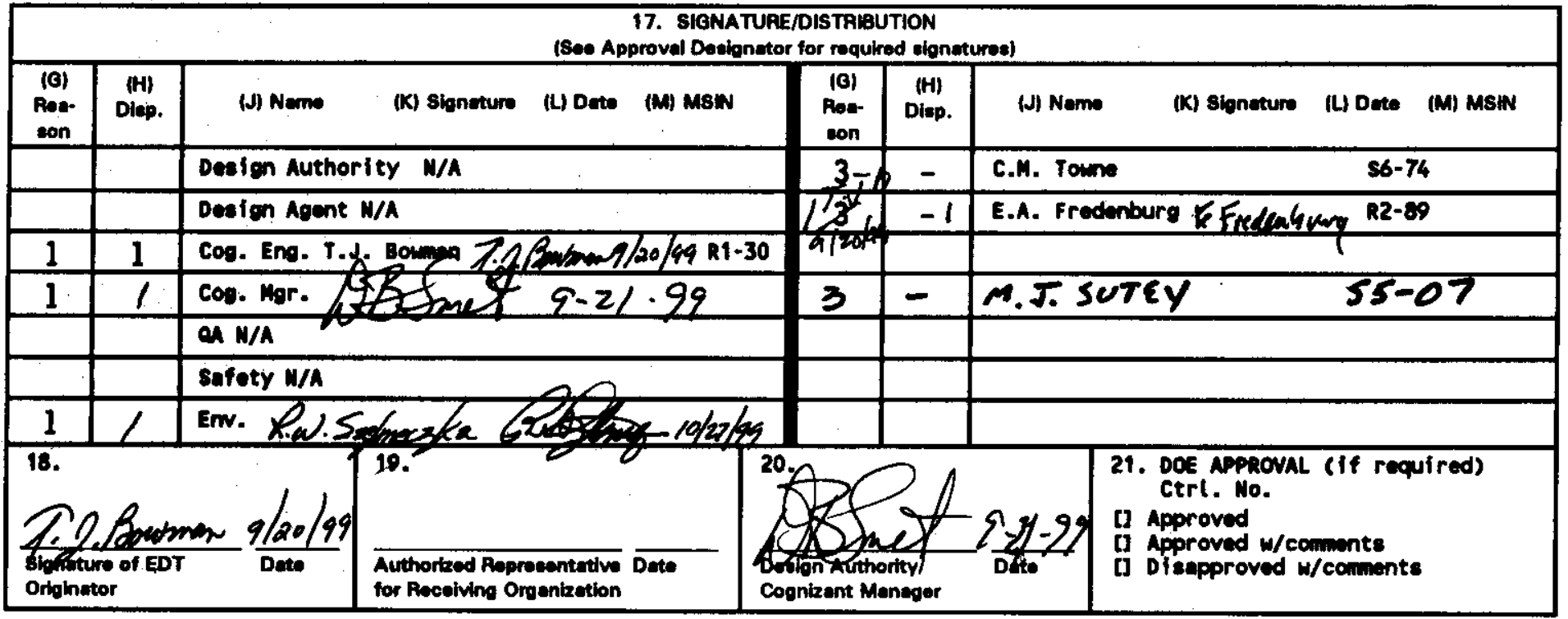

BO-7400-172-2 (05/96) EEF097 
HNF-4689, Rev. 0

\title{
1998 Annual Cathodic Protection Survey Report For the 242-A Evaporator Area
}

\author{
T. J. Bowman \\ Lockheed Martin Hanford Corporation, Richland, WA 99352 \\ U.S. Department of Energy Contract DE-AC06-96RL13200
}

$\begin{array}{ll}\text { EDT/ECN: } 625987 & \text { UC: } \\ \text { Org Code: } 74711 & \text { Charge Code: } 101098 \text { - } 102606 \\ \text { BaR Code: } & \text { Total Pages: } 36\end{array}$

Key Words: cathodic protection, polarization, rectifiers, protected piping, anodes, continuity

Abstract: This report is the second annual cathodic protection report for the 242-A evaporator. The report documents and trends annual polarization survey data, rectifier inspection data, and continuity data from 1994 through mid-1999.

TRADEMARK DISCLAIMER. Reference herein to amy specific comercial product, process, or service by trede nam, tredvemerk, menufecturer, or otherwise, does not necesserily constitute or imply its endorscanent, recomandiation, or favoring by the United states Governent or any aconcy thereof or its contractors or subcentractors.

Printed in the United statee of Amprice. To obtein copies of this document, contact: Docusent Control services, P.0. Dox 950, Mailstop M6-08, Richland WA 99352, Phone (509) 372-2420; fax (509) 376-4989.
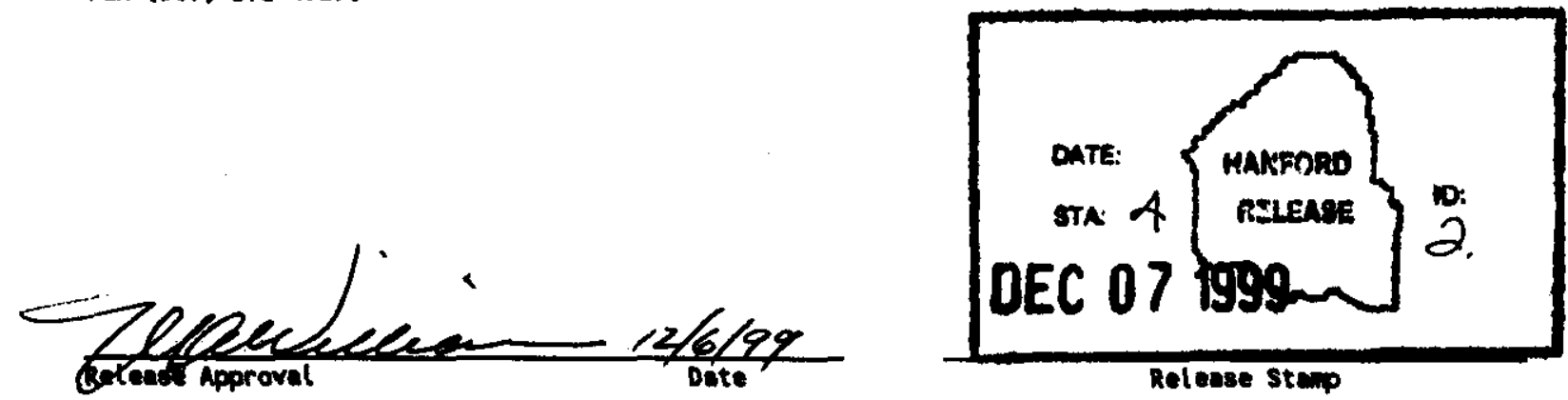

Approved for Public Release 


\section{AMTUL CATHODIC PROTECTIOA SURVEY REPORT TOR THE 242-A EVAPORATOR ARE}

\subsection{TABLE or CONTENTS}

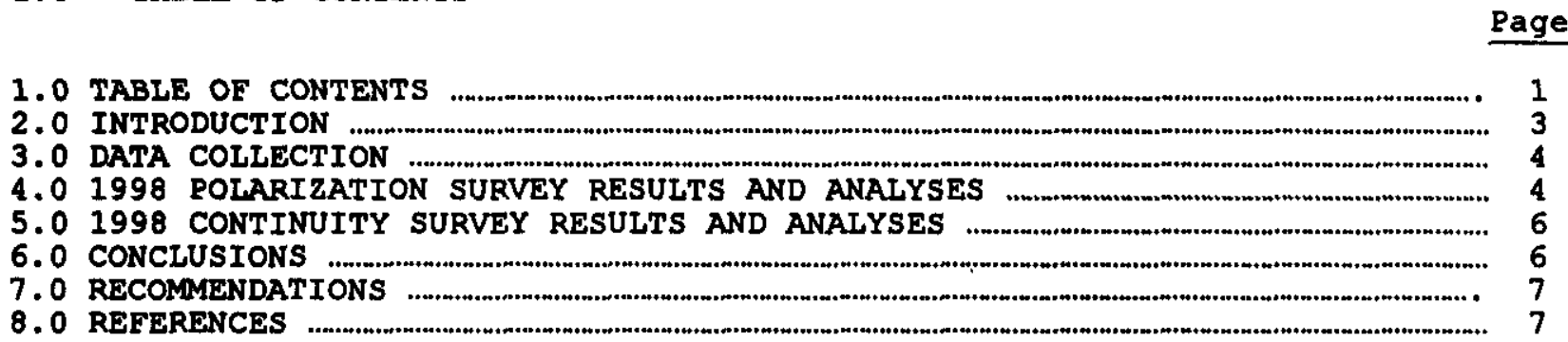

\section{TABLES}

Table 1 - Continuity Testing during the 1998 annual survey ...........................................7

\section{SPREADSHEETS}

Cathodic and Polarized Potentials relative to portable reference ..................... 8 electrode (1994 through 1998 annual surveys)

1998 CP Annual Survey Data

GRAPHS (Cathodic Polarization during 1994 through 1998 annual surveys)

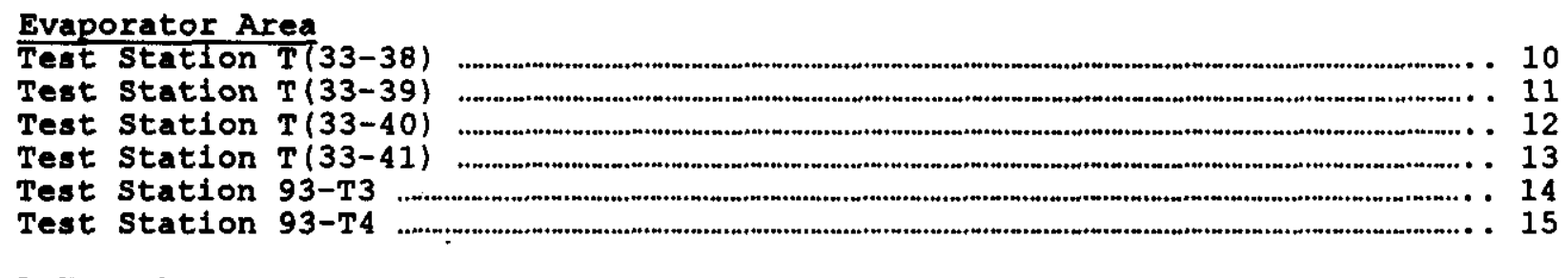

\section{A-Farm Area}

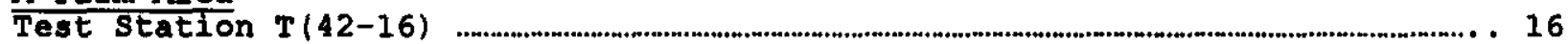

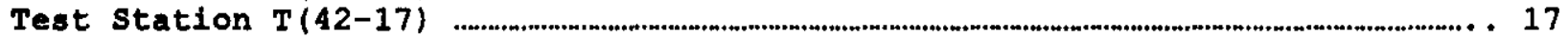

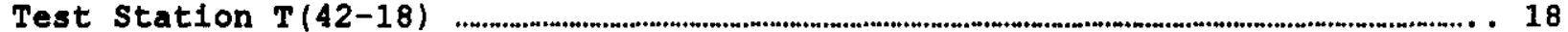

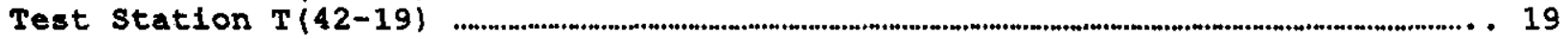

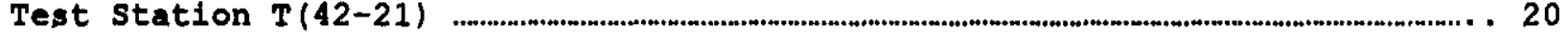

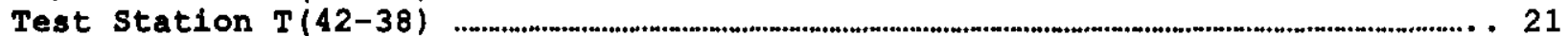

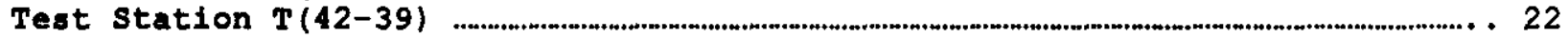

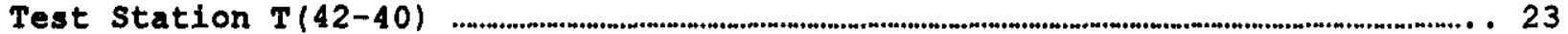

AW-Farm Area

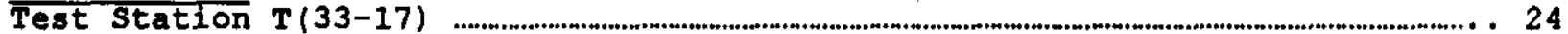

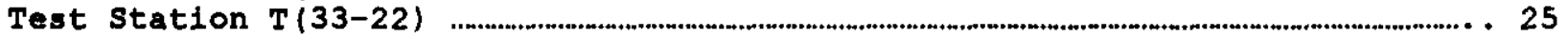

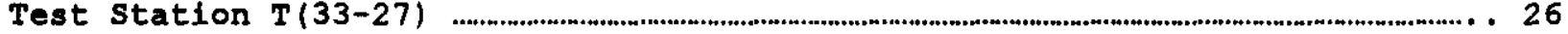

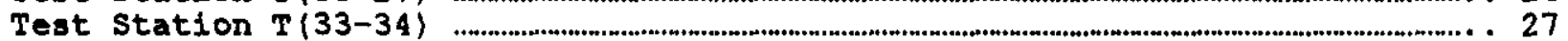

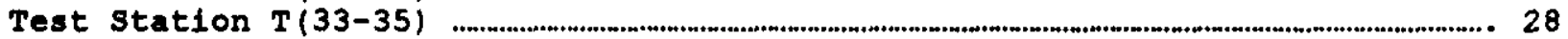

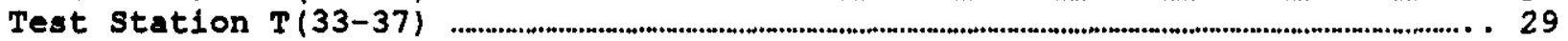

GRAPHS (Rectifier DC Outputs during 1994 to 1998 annual surveys)

EN-RECT-2818 (Rectifier 18) DC volts and amps ........................................................................... 30

Aw241-CATH-RECT-100 (Rectifier 19) DC volts and amps .................................................... 31

AP241-CATH-RECT-100 (Rectifier R1) DC volts and amps ................................................32 
HNT -4689, REV. 0

1998 ANUUAT CATHODIC PROTECTION SURVEY REPORT TOR THE 242-A EVAPORATOR AREA

\subsection{TABIE OF COLTHENTS (contd.)}

GRAPHS (Rectifier Inspections from 1994 to 1998)

Baseline, Resurvey, Bimonthly Inspection EN-RECT-2818 (Rect. \#18).................. 33

Baseline, Resurvey, Bimonthly Inspection AW241-CATH-RECT-100 (Rect. 19) .. 34

Baseline, Resurvey, Bimonthly Inspection AP241-CATH-RECT-100 (Rect. R1) .... 35 
HNT-4689, REV. 0

\section{MTNUAL CATHODIC PROTECTION SURVEY RFPORT} TOR THE 242-A EVAPORATOR ARH

\subsection{IAMroducrion}

This cathodic protection (CP) report documents results of the 1998 CP surveys of the underground piping entering and leaving the 242-A evaporator area. An annual survey of CP systems is required by DOE Order 5820.2A and washington Administrative Code (WAC) 173-303-640.

Two spreadsheets to document the 1994 through 1998 annual survey polarization data are included in this report. Graphs are included to trend the cathodic polarization at each test station from 1994 through 1998 . Graphs are included to trend voltage and amperage outputs of each rectifier during the annual surveys. Graphs are included to trend voltage and amperage outputs of each rectifier during the bimonthly rectifier inspections from 1994 through mid1999. A table is developed to document the lack of continuity between piping at four evaporator test stations.

Analyses of the 1998 annual CP survey are included and conclusions and recommendations are made from the analyses.

Not included in this report is the baseline information developed for the 1997 annual report. The 1997 ANNUAL CATHODIC PROTECTION REPORT FOR THE 242-A EVAPORATOR, HNF-3379 Rev. 0 , contains the following information:

1. A detailed description of the layout of the CP systems and piping systems of the 242-A evaporator;

2. Time sequences involved in the collection of annual survey data from 1994 through 1997 ;

3. CP criteria at Hanford site;

4. River Protection Project (RPP) CP system testing procedure and CP system configurations during annual surveys;

5. 1994 through $1997 \mathrm{CP}$ survey data of voltage and continuity measurements at the test stations of the following areas:

a. 242-A evaporator property;

b. A-Farm property in proximity of the A-Farm valve pits; and

c. AW-Farm property in proximity of the AW-Farm valve pits and in proximity of tanks 241-AW-101 and 241-AW-102;

6. Spreadsheets and tables to tabulate the data, and graphs to trend the data;

7. Bimonthly inspection graph of evaporator Rectifier 18 (EN-RECT-2818) DC voltage and amperage outputs from $7 / 94$ to $7 / 98$;

8. Analysis, conclusions, and recommendations of the 1997 annual CP survey results;

9. Tables listing the attributes of the three rectifier systems associated with the evaporator;

10.Tables listing the attributes of the piping of the evaporator area and associated areas;

11. Table listing continuity measurements at the test stations on evaporator property;

12. Table listing the nameplate output data of the three rectifiers associated with the evaporator;

13. Graphs of three rectifiers DC outputs during the 1994 to 1997 annual surveys;

14. Appendix documenting applicable Washington Administrative Code (WAC) requirements and National Association of Corrosion Engineers (NACE) standard recommended practices pertaining to CP criteria of corrosion protection;

15. Discussion of potential refurbishments required in the year 2005; and

16. References

Page 3 of 35 
ENT-4689, R.V. 0

\subsection{DATA COLIECTION}

The collection of annual survey data and bimonthly inspection data for this report was accomplished as follows:

1998 Test Station Surveys

Data was collected at the direction of the RPP CP cognizant engineer. Testing was performed per Tank Farm Maintenance Procedures 3-CATH-357 Cathodic

Protection System Testing and 3-CATH-357ET Cathodic Protection System Testing

East Tank Farms (ET).

The 1998 annual survey on the evaporator property was performed per work package EL-98-00797.

The 1998 annual surveys on the AW-Farm and A-Farm property were performed per work package 2E-98-1755.

Inspection of EN-RECT-2818 (Rectifier 18), AW241-CATH-RECT-100 (Rectifier 19), and AP241-CATH-RECT-100 (Rectifier R1)

EN-RECT-2818 (Rectifier 18) was inspected on a bimonthly basis by the

evaporator personnel per Tank Farm Maintenance Procedure, 6-TF-221, Inspection of Cathodic Protection System Rectifiers.

AW241-CATH-RECT-100 (Rectifier 19) and AP241-CATH-RECT-100 (Rectifier R1) were inspected on a bimonthly basis by the east tank farm personnel per Tank Farm Maintenance Procedure, 6-TF-221, Inspection of Cathodic Protection system Rectifiers.

CP system Configuration During Annual survey

Rectifiers EN-RECT-2818 (18), AW241-CATH-RECT-100 $\quad$ (19), AP241-CATH-RECT-100 (R1), 15, and 16 were equipped with pulse generators during the annual surveys. The pulse generators allow the "polarized potential" across the piping to be calculated. The pulse generators are specified as not drifting and do not have to be synchronized with each other.

Rectifier AP241-CATH-RECT-100 (R1) system was operating with a non-pulsing pulse generator during the 1997 annual survey. The resulting uninterrupted current affected the polarization measurements at two test stations in the evaporator area. However, correlation with 1996 survey readings allowed the polarized potentials to be estimated. The estimated polarized potentials are shown on the graphs of test stations 93-T3 and 93-T4.

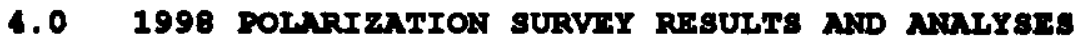

Rectifier Outputs Influencing Voltages at Evaporator Area Test stations Cathodic polarization across underground piping is measured at $s i x$ test stations in the evaporator area. EN-RECT-2818 (Rectifier 18) and AP241-CATHRECT-100 (Rectifier R1) systems created the bulk of the polarization values at the six test stations. EN-RECT-2818 (Rectifier 18) system was running at 18.9 amps (nameplate $=40$ amps) and AP241-CATH-RECT-100 (Rectifier R1) system was running at 20.9 amps (nameplate $=60$ amps) during the 1998 annual survey.

Polarization voltages at test stations $\mathrm{T}(33-38), \mathrm{T}(33-39), 93-\mathrm{T} 3,93-\mathrm{T} 4$ Measurements at four of the six test stations showed that the underground piping was protected above the NACE RP0285-95 4.2.1.2 standard (a negative polarized potential of at least 850 millivolts relative to a saturated copper/copper sulfate electrode). Reference the polarization graphs of test stations $T(33-38), T(33-39), 93-T 3$, and 93-T4. The four-year polarization trends at these test stations shows fairly constant polarization values. The OFF polarization values at $93-T 3$ and $93-T 4$ during the 1997 survey are skewed because the AP241-CATH-RECT-100 rectifier was not pulsing due to a faulty pulse generator.

$$
\text { Page } 4 \text { of } 35
$$


HINT-4689, REV. 0

Polarization voltages at test stations $\mathrm{T}(33-40), \mathrm{T}(33-41)$

Measurements at the other two test stations on the evaporator property gave polarization values of -0.77 and -0.58 volts across the underground piping. Reference the polarization graphs of test stations $T(33-40)$ and $T(33-41)$. Polarization at $T(33-40)$ increased by 40 millivolts from the 1997 value. Polarization at $T(33-41)$ dropped by 150 millivolts from the 1997 value.

Native potentials of the underground piping have not been measured at the two test stations. The average native potential of the east area is between -0.3 to -0.35 volts. Assuming that the native potential of the underground piping at the two test stations is -0.35 volts, the piping at these two test stations gained at least 230 millivolts of polarization. NACE RP0285-95 4.2.1.3 standard (a minimum of $100 \mathrm{mV}$ of cathodic polarization) would be exceeded by 130 millivolts.

A-Farm Valve Pit Area Test Stations Cathodic polarization across underground piping is measured at eight EN-RECT2818 (Rectifier 18) test stations in the A-Farm area. EN-RECT-2818 (Rectifier 18) system created the bulk of the polarization values across the piping at six of the eight test stations and contributed significantly to the polarization values across the piping at two of the test stations. EN-RECT2818 (Rectifier 18) system was running at 18.9 amps (nameplate $=40$ amps) during the 1998 annual survey. Rectifier 15 system and Rectifier 16 system contributed significantly to the polarization values across the piping at five test stations.

Polarization voltages at test stations $T(42-16), T(42-17), T(42-19), T(42-21)$, $\mathrm{T}(42-38), \mathrm{T}(42-39), \mathrm{T}(42-40)$

Measurements at seven of the eight test stations showed that the underground piping was protected above the NACE RP0285-95 4.2.1.2 standard (a negative polarized potential of at least 850 millivolts relative to a saturated copper/copper sulfate electrode). Reference the polarization graphs of test stations $T(42-16), T(42-17), T(42-19), T(42-21), T(42-38), T(42-39)$, and $T(42-$ 40). The four-year polarization trends at these test stations shows fairly constant polarization values.

The operation of Rectifier 15 system and Rectifier 16 system contributed significantly to the polarization values across the piping at test stations $T(42-16), T(42-17), T(42-18), T(42-21), T(42-40)$.

Polarization voltage at test stations $T(42-18)$

Cathodic measurements across the piping at one test station gave a polarization value of -0.813 volts. Reference the polarization graph of test station $T(42-18)$. The four-year polarization trend at test station $T(42-18)$ shows a moderate polarization loss.

A native potential of the piping has not been measured at the test station. At an assumed native potential of -0.35 volts, the piping at the test station would have gained 463 millivolts of polarization. NACE RP0285-95 4.2.1.3 standard (a minimum of $100 \mathrm{mV}$ of cathodic polarization) would be exceeded by 363 millivolts.

Aw-Earm (Valve Pit Area, Tank 101 Area and Tank 102 Area) Test stations Cathodic polarization is measured across the evaporator and A-Farm piping at six test stations in the AW-Farm area. AW241-CATH-RECT-100 (Rectifier 19) system created the bulk of the polarization values at the six test stations. AW241-CATH-RECT-100 (Rectifier 19) system was running at 5.75 amps (nameplate $=12$ amps) during the 1998 annual survey.

Polarization voltage at test stations $T(33-22), T(33-37), T(33-35), T(33-34)$,

Page 5 of 35 
gns-4689, Rrv. 0

$\mathrm{T}(33-27)$

Measurements at five of the six test stations showed that the underground piping was protected above the NACE RP0285-95 4.2.1.2 standard (a negative polarized potential of at least 850 millivolts relative to a saturated copper/copper sulfate electrode). Reference the polarization graphs of test stations $T(33-22), T(33-37), T(33-35), T(33-34)$, and $T(33-27), T(33-22)$ gained $220 \mathrm{millivolts}$ of polarization from 1994 to 1998 . The four-year polarization trends at the other four test stations shows fairly constant polarization values.

Polarization voltage at test stations $\mathrm{T}(33-17)$

Measurements at one of the $\mathbf{s i x}$ test station gave a polarization value of -0.70 volts in 1997. Reference the polarization graph of teat station T(33-17). The test station was inaccessible during the 1998 survey.

A native potential of the piping has not been measured at the test station. At an assumed native potential of -0.35 volts, the piping at the test station would gain 350 millivolts of polarization. NACE RP0285-95 4.2.1.3 standard (a minimum of $100 \mathrm{mV}$ of cathodic polarization) would be exceeded by 250

millivolts.

\subsection{CONYINUITY SURVEY RESULTS MND MALYSES}

Continuity measurements were performed in 1998 at all aix of the CP test stations located on the evaporator property. The continuity measurements that were greater than 100 ohms between piping conductors are tabulated in Table 1.

The underground piping connected to the "Resistive terminals" of Table 1 is not bonded to the "Specified Test Terminals" of Table 1.

\section{0 cosctusions}

Evaporator in-RrCr-2818 (Rectifier 18) operation During the 1998 annual survey, the rectifier was running at $15 \%$ of its kilowatt DC output capacity. At this low output, the rectifier is running at $45 \%$ efficiency. This efficiency is commonplace for low kilowatt output percentages.

The rectifier was running at 39.2 DC volts and 18.9 DC amps, or $1 / 3$ the nameplate voltage of 120 DC volts and $1 / 2$ the nameplate amperage of 40 DC amps.

As the underground anodes deteriorate, the system resistance would increase and more voltage would be required for the same amperage. The rectifier has ample voltage left, $1 . e ., 80$ volts, to compensate for any future anode deterioration. The EN-RECT-2818 (Rectifier 18) system was installed in 1985 and a slight system resistance increase has been shown over the last three years. The rectifier voltage has remained constant at the same tap settings.

Evaporator IA-RRCT-2818 (Rectifier 18) aystem operation

All piping originating on the evaporator property, i.e., DR-335, DR-334, DR343, DR-338, SI-168, SN-269, SN-270, SL-113, SI-114, and SL-167, and designed to be protected by the EN-RECT-2818 (Rectifier 18) system, is protected to the NACE standards implicitly recommended in the wAC. The aforementioned piping is protected within the evaporator area by EN-RECT-2818 (Rectifier 18) system. DR-335, DR-334, DR-343, SL-114, and SL-113 are also protected within A-Farm by EN-RECT-2818 (Rectifier 18) system.

All piping originating on the A-Farm property, i.e., SN-220, 5N-219, 4001, 4004, SL-100, SL-101, SN-215, SN-216, AND LIQW-702, and designed to be protected by the EN-RECT-2818 (Rectifier 18) system, is protected to the NACE standards implicitly recommended in the WAC.

$$
\text { Page } 6 \text { of } 35
$$


IDT-4689, REV. 0

NP-Ferm NP241-CAMH-RECT-100 (Rectifier RI) system operation Piping SN-650, originating from AP-Farm, is designed to be protected by the AP241-CATH-RECT-100 (Rectifier R1) system on Evaporator property and 1s protected to the NACE standards implicitly recommended in the wAC.

\section{AH-Iarm AN241-CAHt-RECr-100 (Rectifier 19) system operation}

All piping originating on the evaporator property or A-Farm property that enters $A W$-Farm from the evaporator property, i.e., DR-335, DR-334, DR-343, SL-168, SN-269, SN-270, SL-167, SN-220, and SN-219, is protected to the NACE standards implicitly recommended in the WAC. The aforementioned piping is protected within AW-Farm by EN-RECT-2818 (Rectifier 19) system.

\section{Bonding on Eveporator Property}

All the identified "Resistive terminals" in the test stations of Table 1 require bonding jumpers to be installed between the "Resistive Terminals" and the "specified Test Terminals" (or equivalent path) of Table 1.

\subsection{RECOMANDRTIONS}

Leave tap settings of Rectifier 18 at $B-1$.

Attached bonding jumpers between the aforementioned terminals of Table 1 .

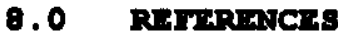

HNF-3379 Rev. 0, 1997 Annual Cathodic Protection survey Report for the 242-A Evaporator

NACE Standard RP0285-95, Item No. RP02085-95, Standard Recommended Practice, Corrosion Control of Underground Storage Tank Systems by Cathodic Protection H-2-91042 Sh 1 Rev. 3 - Cathodic Protection Plot Plan Test Stations and Jumpers

H-2-91042 Sh 2 Rev. 3 - Cathodic Protection Plot Plan Anode Installation H-2-91033 Sh 1 Rev. 2 - Cathodic Protection Plot Plan Test stations and Jumpers

H-2-91033 Sh 2 Rev. 1 - Cathodic Protection Plot Plan Anode Installation H-2-76993 Sh 1 Rev. 1 - Electrical Cathodic Protection Plan \&et WAC 173-303-640 Tank Systems, Washington State Department of Ecology. Dangerous Waste Regulations, Chapter 173-303 WAC, Publication 92-91

THEIT 1

Continuity resting during 1998 annual eurvay

\begin{tabular}{|c|c|c|}
\hline Test station & Specified Test Terminals & $\begin{array}{l}\text { Resistive Terminals (> } 100 \\
\text { ohms in conductive path) and } \\
\text { their resistance value to } \\
\text { the Specified Test Terminals }\end{array}$ \\
\hline$T(33-38)$ & $5 \& 6$ & $\begin{array}{l}1 \& 2 \text { at } 1.2 \text { Mohms } \\
13 \& 14 \text { at } 3.1 \text { Mohms }\end{array}$ \\
\hline $\mathrm{T}(33-39)$ & $5 \& 6$ & $13 \& 14$ at 6.8 Mohms \\
\hline$(93-\mathrm{T} 4)$ & $1 \& 2$ & $\begin{array}{l}9 \& 10 \text { at } 20 \text { Kohms } \\
11 \& 12 \text { at } 10 \text { Mohms }\end{array}$ \\
\hline$(93-T 3)$ & $5 \div 6$ & $\begin{array}{l}3 \& 4 \text { at } 1.1 \text { Mohms } \\
1 \& 2 \text { at } 0.8 \text { Mohms } \\
9 \& 10 \text { at OPEN circuit } \\
11 \& 12 \text { at OPEN circuit }\end{array}$ \\
\hline
\end{tabular}




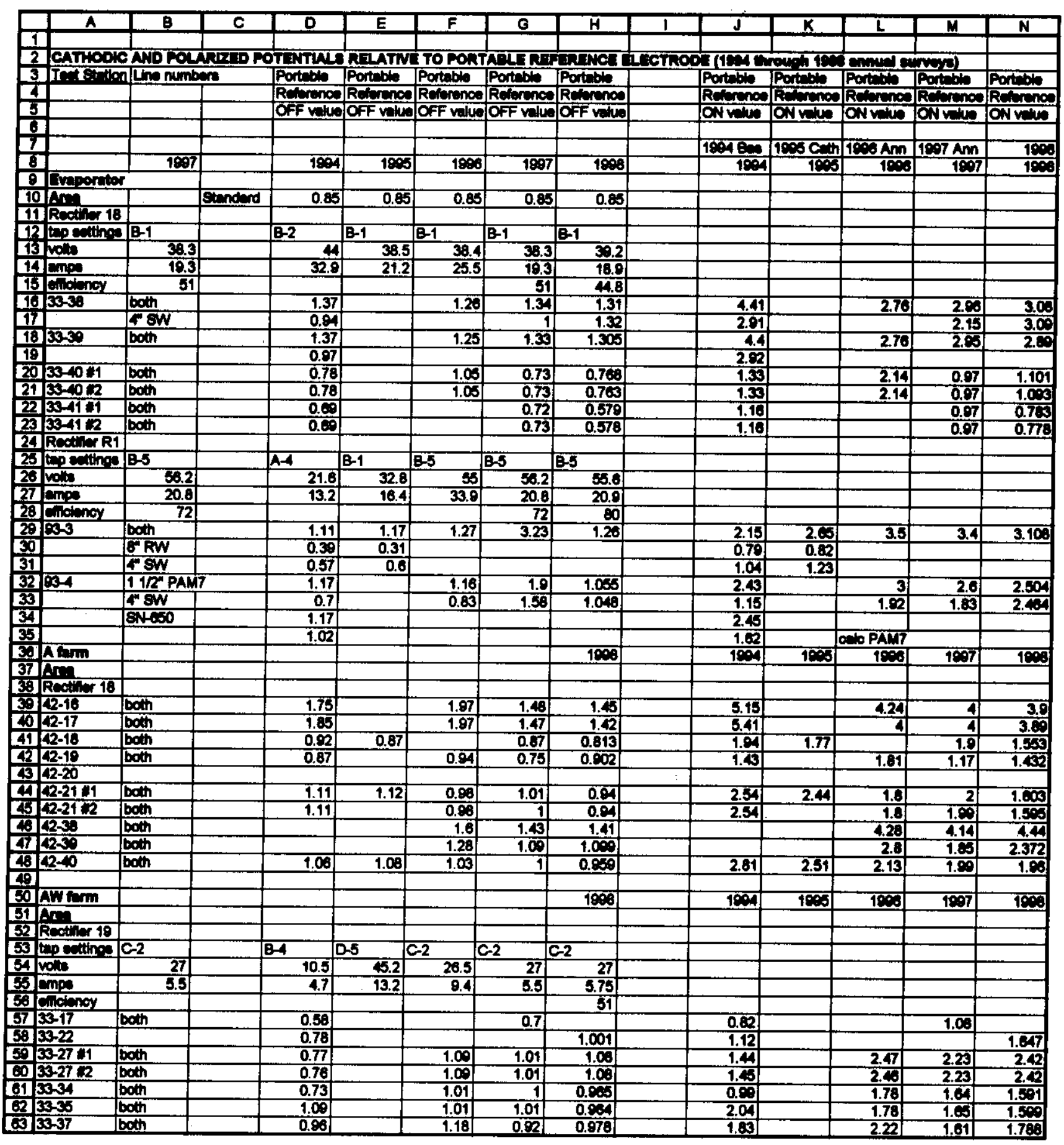




\begin{tabular}{|c|c|c|c|c|c|c|c|c|c|c|c|c|c|}
\hline & $\mathbf{A}$ & $B$ & $\mathrm{C}$ & 0 & $E$ & $F$ & $\theta$ & $H$ & 1 & $J$ & $\mathbf{K}$ & L & $\mathbf{M}$ \\
\hline 1 & SFIJDSH & $575 \cdot 100 \mathrm{C}$ & Anmeal sur & molon & & & & & & & & & \\
\hline 2 & ITCAA & nl suny bon & & & & & & & & & & & \\
\hline 3 & Iretstim & tomine & Potshe & Portobis & Formanent & Permanen & Portebs to & Portabio to & & Permenten & Permenn & Fortabion & Portaing to \\
\hline 4 & & numbere & Reterenos & Reforence & Relerence & Relerenos & Permanent & Permenent & & Recerence & Recrenos & Perminam & Primenen \\
\hline 5 & & & ONveres & CFir valus & ON velue & OrF velue & ON velue & OFF value & & ON vine & Gif van & ONveres & Oriprolue \\
\hline 6 & & & & & & & & & & & & & \\
\hline 7 & & & 1097 Anmu & Cothodic & Protection S & Survey Data & & & & & & & \\
\hline 8 & & 190 & 100 & 1000 & 1908 & 1008 & 1008 & 190 & $1 \%$ & 193 & 403 & 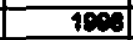 & $1 \%$ \\
\hline 5 & Everorator & & & & & & & & & & & & \\
\hline 10 & A & & & & & & & & & & & & \\
\hline 11 & | Rectiver 18 & & & & & & & & & & & & \\
\hline 12 & tepeviline & 8-1 & & & & & & & & & & & \\
\hline 13 & volns & 30.2 & & & & & & & & & & & \\
\hline 14 & Cnis & 10.0 & & & & & & & & & & & \\
\hline 15 & 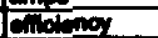 & 44.0 & & & & & & & & & & & \\
\hline 10 & $33-3$ & 80 & 3.0 & 1.31 & 2.72 & 1.21 & 0.38 & 0.1 & & & & & \\
\hline 17 & & 34 & 3.0 & 1.32 & 1.02 & 0.73 & 1.22 & 0.40 & & & & & \\
\hline 18 & $33-3$ & Finend 34 & 20 & 1.30 & 1,46 & 0.87 & 1.44 & 0.41 & & 2.01 & 1.10 & 0.10 & 0.03 \\
\hline 10 & & & & & & & & & & & & & \\
\hline 20 & 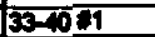 & 334 and 182 & 1.101 & 0.70 & 0.330 & 0.321 & 0.743 & 0.427 & & & & & \\
\hline 21 & $33-10=2$ & Sxe end 34 & 1.003 & 0.703 & 1.407 & 0.831 & -0.307 & -0.043 & & & & & \\
\hline $\mathbf{2} 2$ & $33-4101$ & Exs end 344 & $0.7 \times$ & 0.670 & 0.75 & 0.533 & 0.033 & 0.041 & & & & & \\
\hline 23 & $33-412$ & M1011812 & 0.778 & 0.678 & 0.837 & 0.533 & -0.088 & 0.004 & & & & & \\
\hline 24 & Rectiver R1 & & & & & & & & & & & & \\
\hline 25 & tepentin's & $8-6$ & & & & & & & & & & & \\
\hline 20 & $\operatorname{mos}$ & 8.6 & & & & & & & & & & & \\
\hline 27 & inges & 20.9 & & & & & & & & & & & \\
\hline 28 & filoingy & 80 & & & & & & & & & & & \\
\hline 20 & 033 & Fen and 3h4 & 3.100 & 120 & 2.743 & 1.322 & 0.372 & 0.003 & & 3.42 & 1.24 & -0.3 & 0.013 \\
\hline 30 & & SRW & & & & & & & & & & & \\
\hline 31 & & $6 \mathrm{gW}$ & & & & & & & & & & & \\
\hline 32 & 03 & 182 & 2.504 & 1.030 & & & & & & 2.03 & 1.00 & 0.43 & -0.018 \\
\hline 33 & & O10 & 2.44 & 1.040 & & & & & & & & & \\
\hline 34 & & SN-60 & & & m? & $m$ & & & & & & & \\
\hline 33 & & & & & & & & & & & & & \\
\hline 33 & Afam & 103 & 103 & $1 \%$ & 108 & 100 & 1008 & $19: 3$ & 1098 & $1 \%$ & 193 & $1 \%$ & \\
\hline 37 & $A B$ & & & & & & & & & & & & \\
\hline 33 & Rectivier 18 & & & & & & & & & & & & \\
\hline 30 & 42.18 & 324 and 182 & 3.0 & 1.46 & $3 . \%$ & 1.33 & 0.007 & 0.007 & & & & & \\
\hline 40 & 42.17 & Fes and 324 & 3.80 & 1.42 & $3.0 \times 3$ & 1.206 & 0.033 & 0.237 & & & & & \\
\hline 41 & 2.18 & Fes and 394 & 1.63 & 0.813 & 2.151 & 0.925 & -0.500 & -0.004 & & & & &. \\
\hline 42 & 42.10 & Bres end 34 & 1.452 & 0.002 & 1.581 & 1.022 & -0.154 & -0.12 & & 1.430 & 0.84 & -0.011 & 0.037 \\
\hline 43 & $42-20$ & & & & & & & & et 42-24 & & & & \\
\hline 44 & 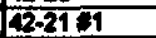 & 324 and 182 & 1.000 & 0.1 & 0.878 & 0.072 & 0.710 & 0.204 & & & & & \\
\hline 45 & 42.212 & 142010 & 1.09 & D.4 & 1.477 & 0.678 & 0.100 & 0.063 & & & & & \\
\hline 48 & 423 & Fend 34 & 4.44 & 1.41 & 4.1 & 1.34 & 0.335 & 0.001 & & & & & \\
\hline 47 & $12-30$ & S send 34 & 2.372 & 1.000 & 0.802 & 0.716 & 1.567 & 0.377 & & & & & \\
\hline 48 & $42-10$ & ST end 34 & 1.80 & 0.50 & 2.017 & 0.842 & -0.073 & 0.01 & & & & & \\
\hline 40 & & & & & & & & & & & & & \\
\hline 50 & AWfam & 100 & 1003 & 100 & 1928 & 100 & 190 & 100 & $1 \% 3$ & 1008 & $T$ & 100 & 193 \\
\hline 51 & Ar: & & & & & & & & & & & & \\
\hline 62 & Rectiver 19 & & & & & & & & & & & & \\
\hline 3 & tap extin's & $\mathrm{C-2}$ & & & & & & & & & & & \\
\hline 5 & rolite & 27 & & & & & & & & & & & \\
\hline 3 & angs & 8.73 & & & & & & & & & & & \\
\hline $\mathbf{3}$ & Cliotiongy & 51 & & & & & & & & & & & \\
\hline 67 & $3 x-17$ & & & & & & & & cownerd & & & & \\
\hline 88 & $33-22$ & ERe end $3 \mathrm{M} 4$ & 1.947 & 1.001 & 2.004 & 0.061 & -0.381 & 0.011 & & & & & \\
\hline 50 & $33-27 \cap 1$ & Foend 324 & 2.42 & 1.00 & 2.103 & 0.974 & 0.220 & 0.105 & & & & & \\
\hline 6 & $33-27 / 2$ & 384 and 162 & 2.42 & 1.00 & 2.421 & 1.03 & 0.204 & 0.048 & & & & & \\
\hline 81 & 3334 & OS10/1912 & 1.61 & 0.00 & 1.507 & 0.634 & 0.300 & 0.076 & & 1.30 & 0.822 & 0.122 & 0.133 \\
\hline$\dot{2}$ & $33-35$ & S.6 and 344 & 1.60 & 0.04 & 1,000 & 0.830 & -0.301 & 0.070 & & & & & \\
\hline (3) & $33-37$ & Bor and 384 & 1.705 & 0.978 & 1.701 & 0.0 & 0.026 & -0.010 & & & & & \\
\hline
\end{tabular}




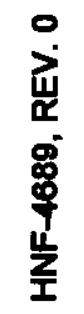
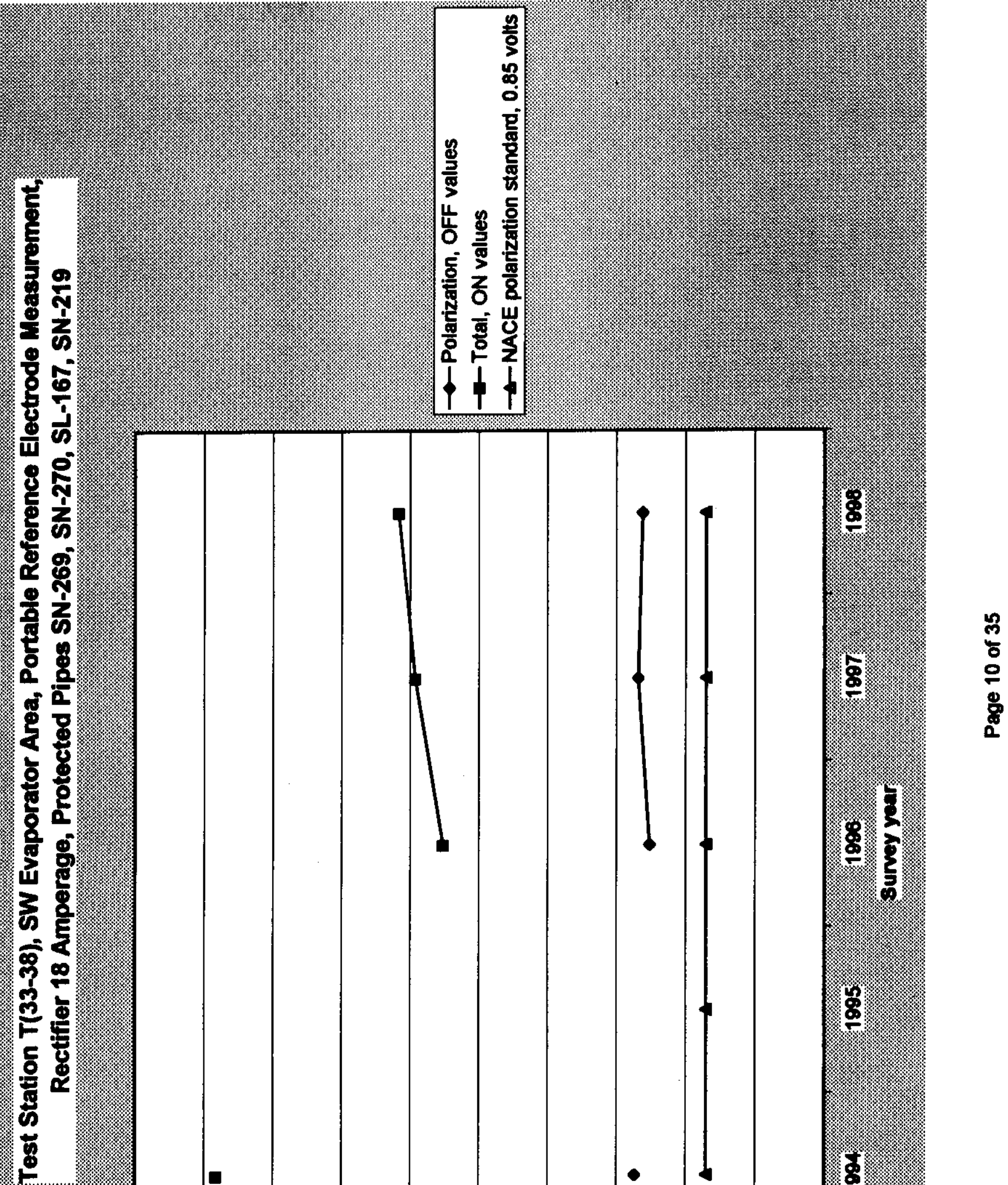
0
竞
8
8
$\frac{8}{9}$
$\frac{1}{2}$
$\frac{1}{2}$
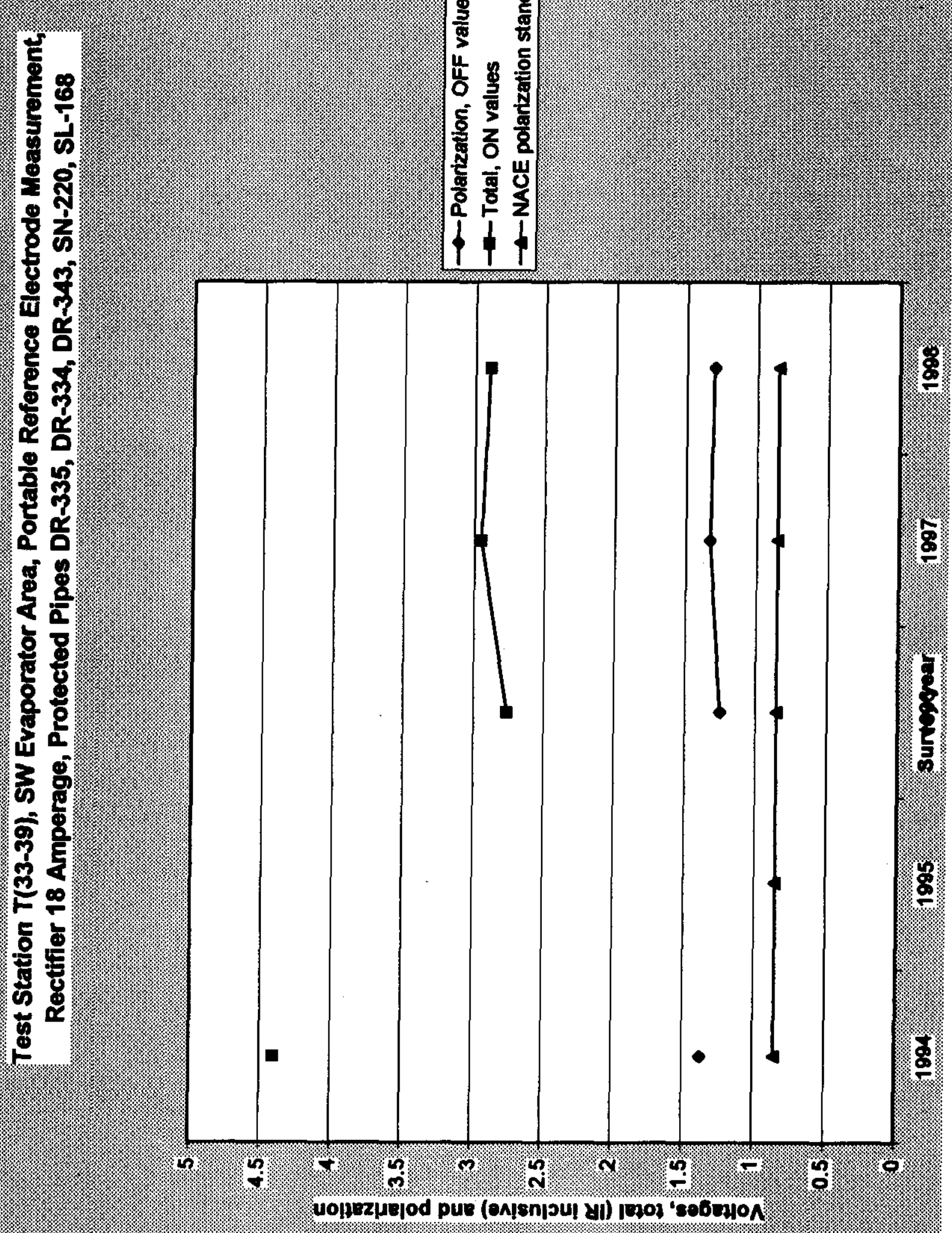
离

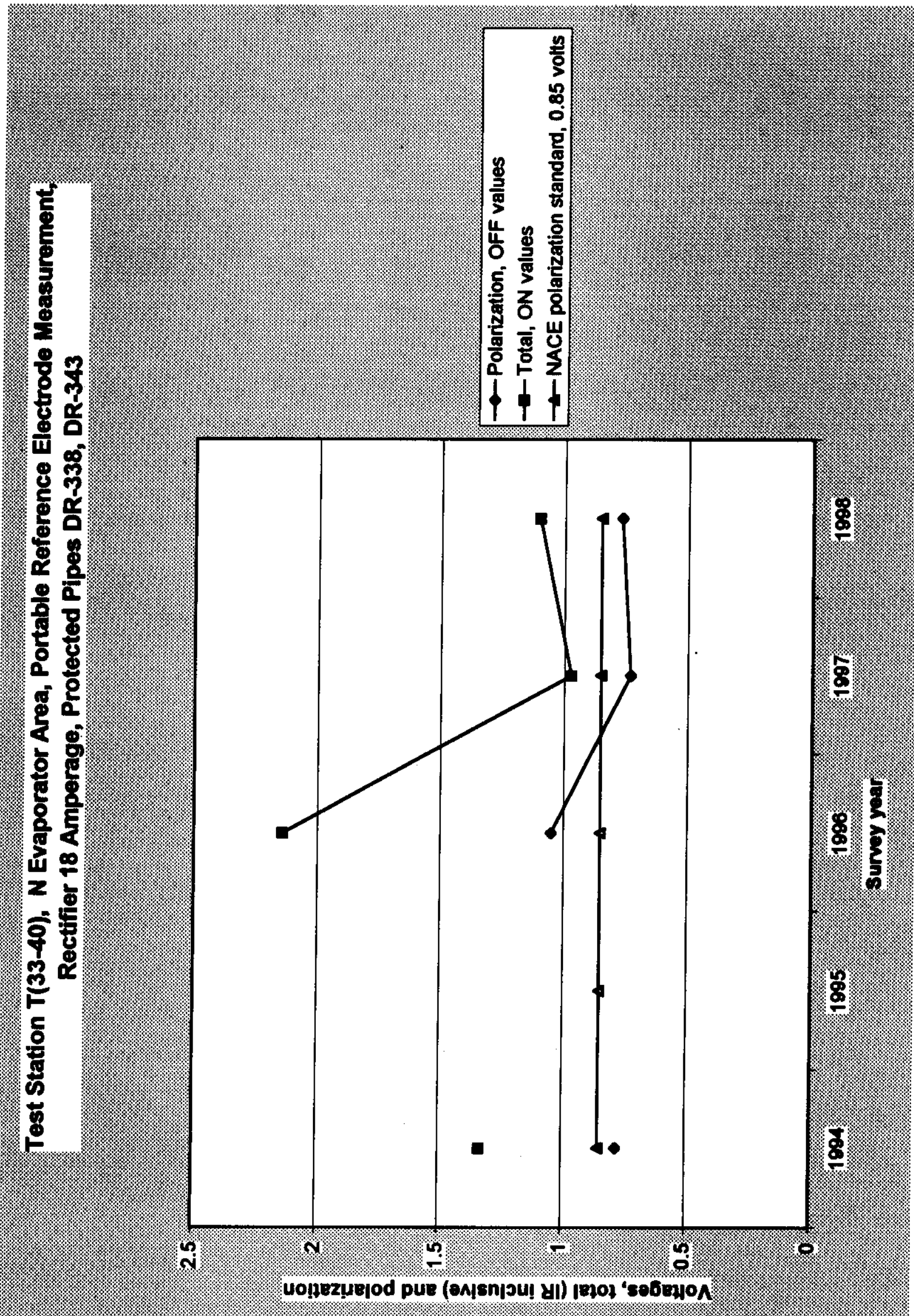

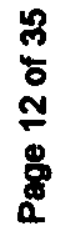


竞
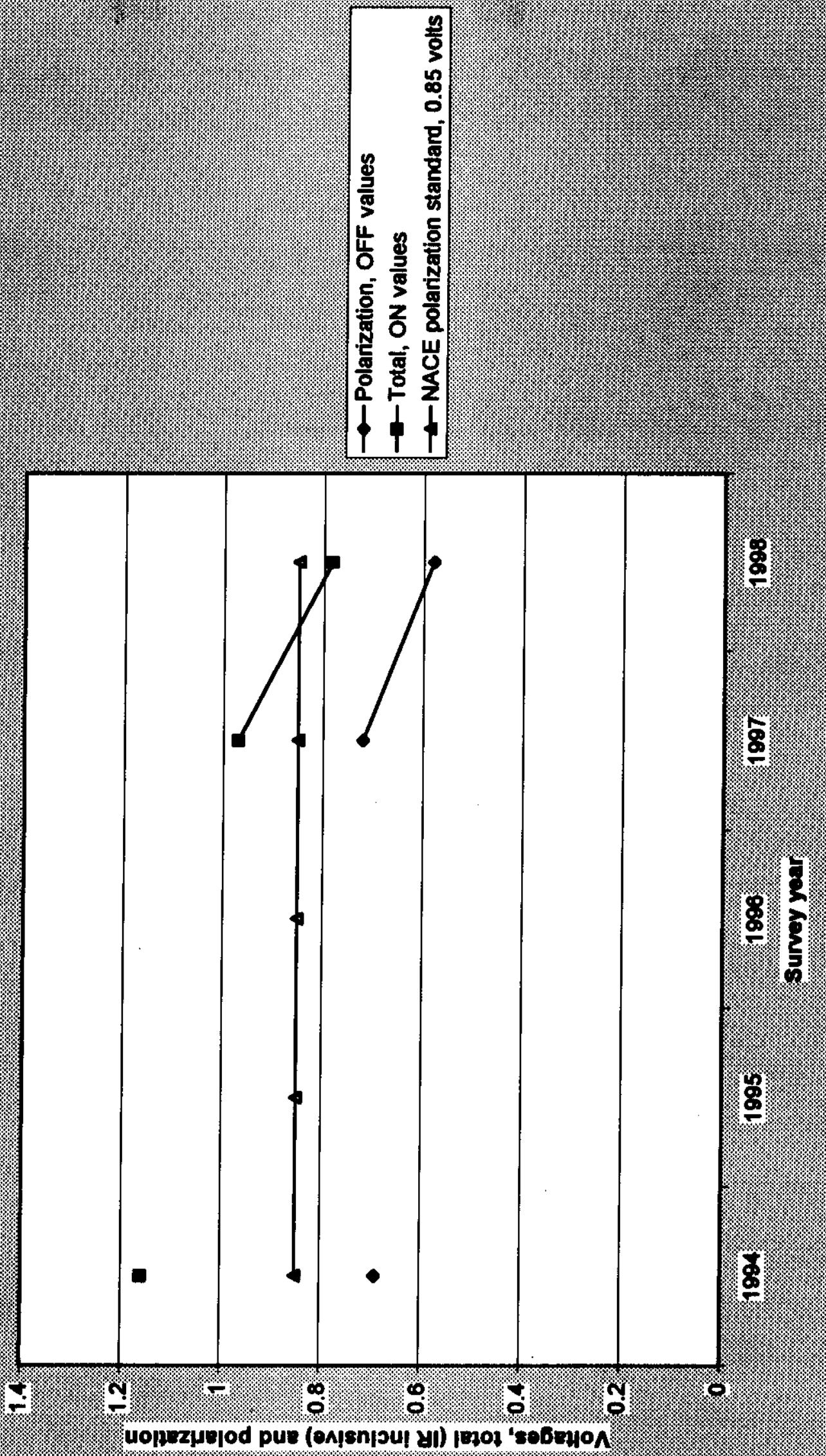

0
8
0
0
8
8
0 


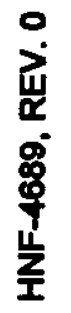
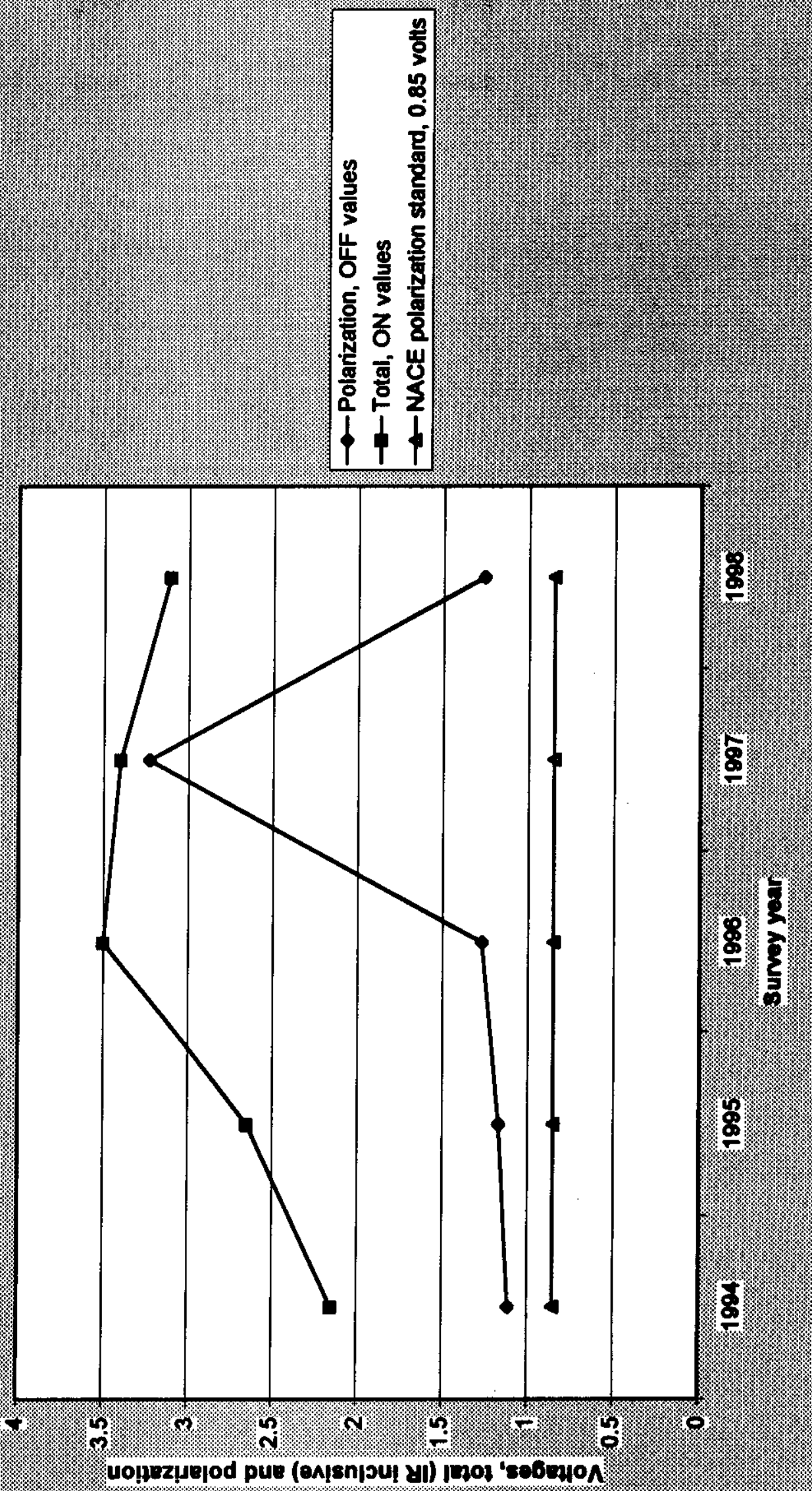


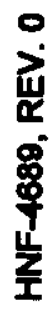

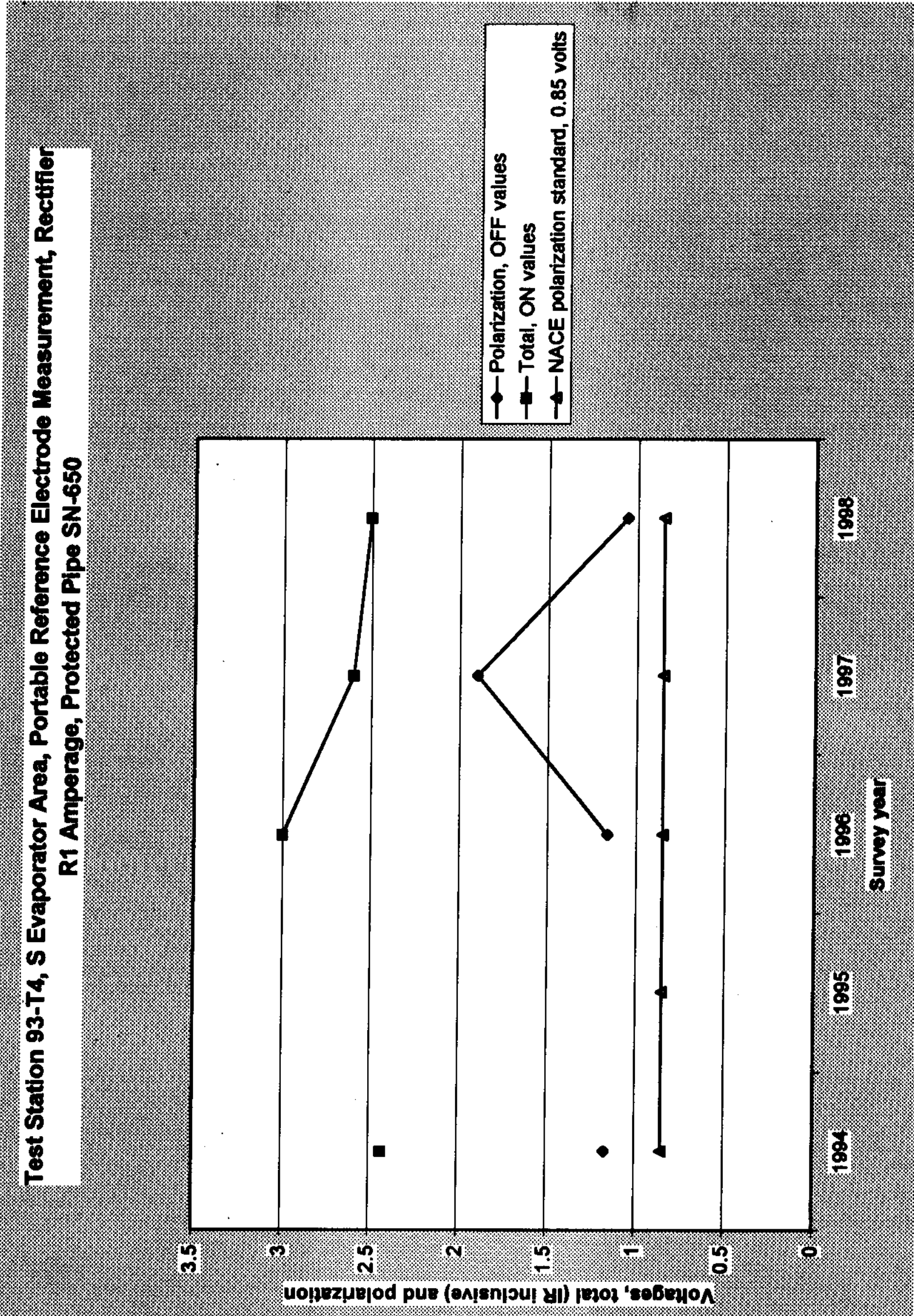

5
5
0
0
$\vdots$
0
0 


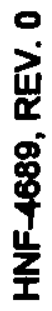

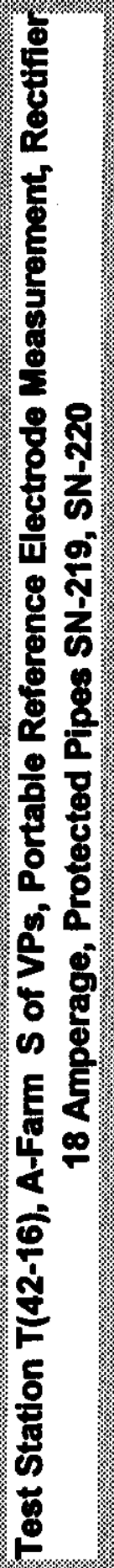

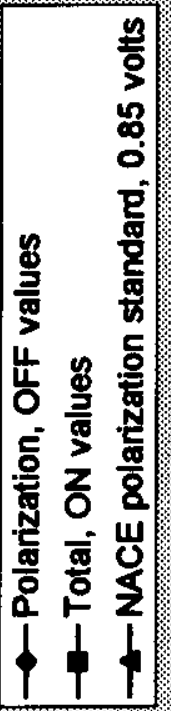

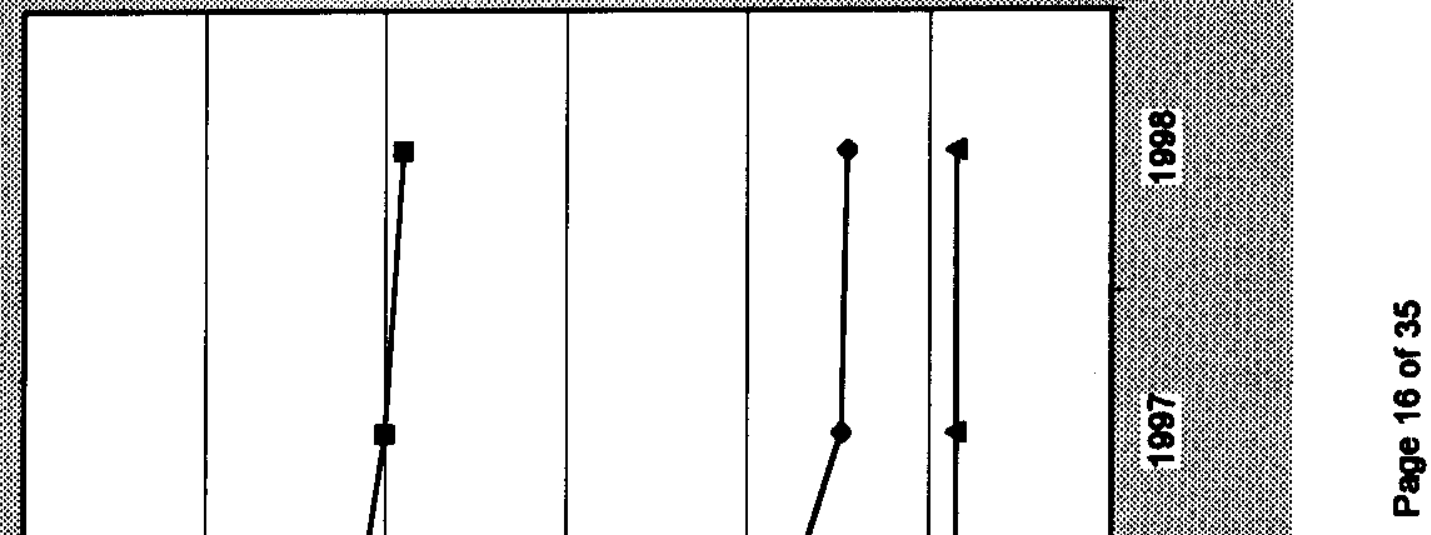




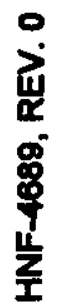
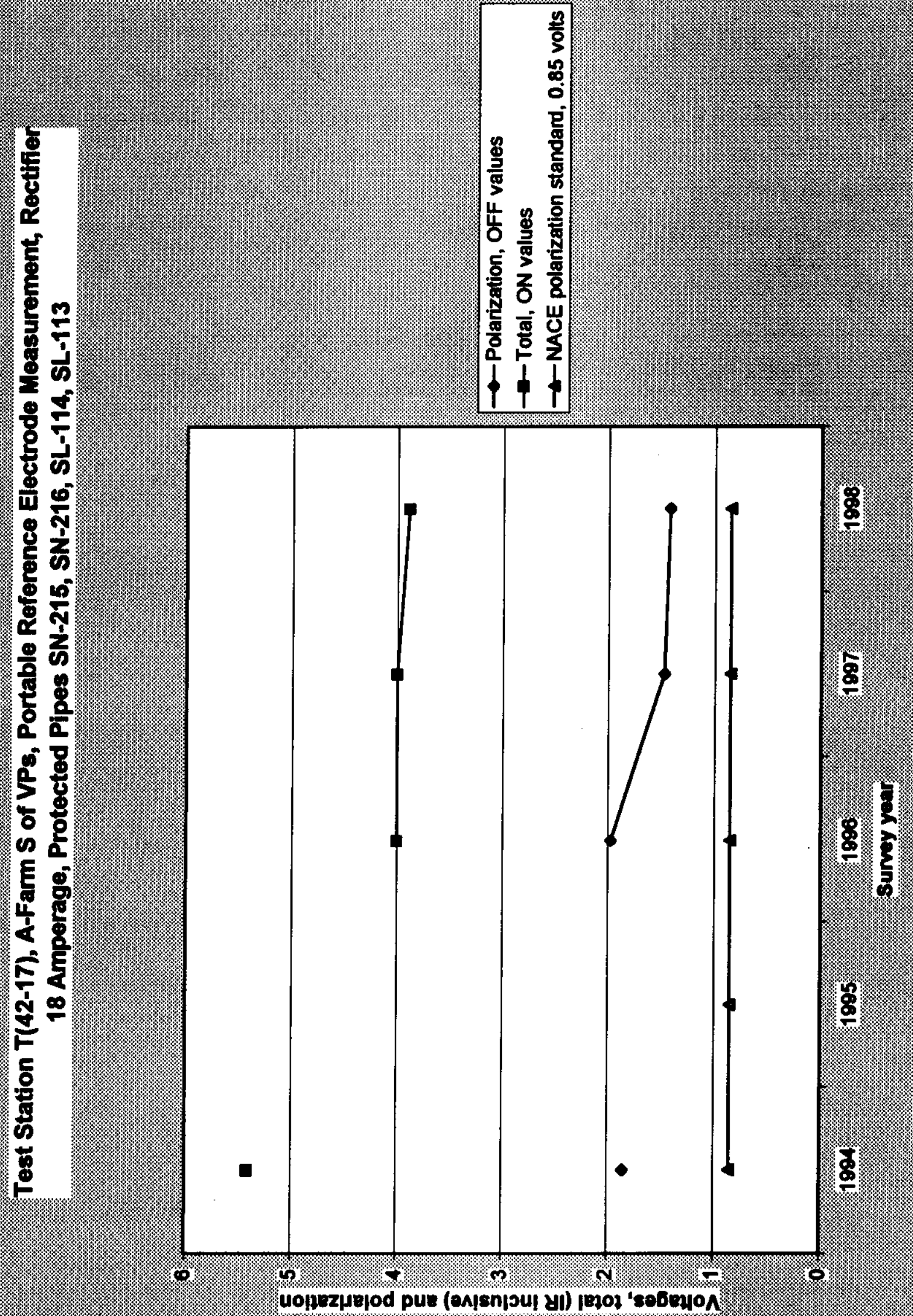

8
5
5
8
8 


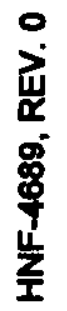
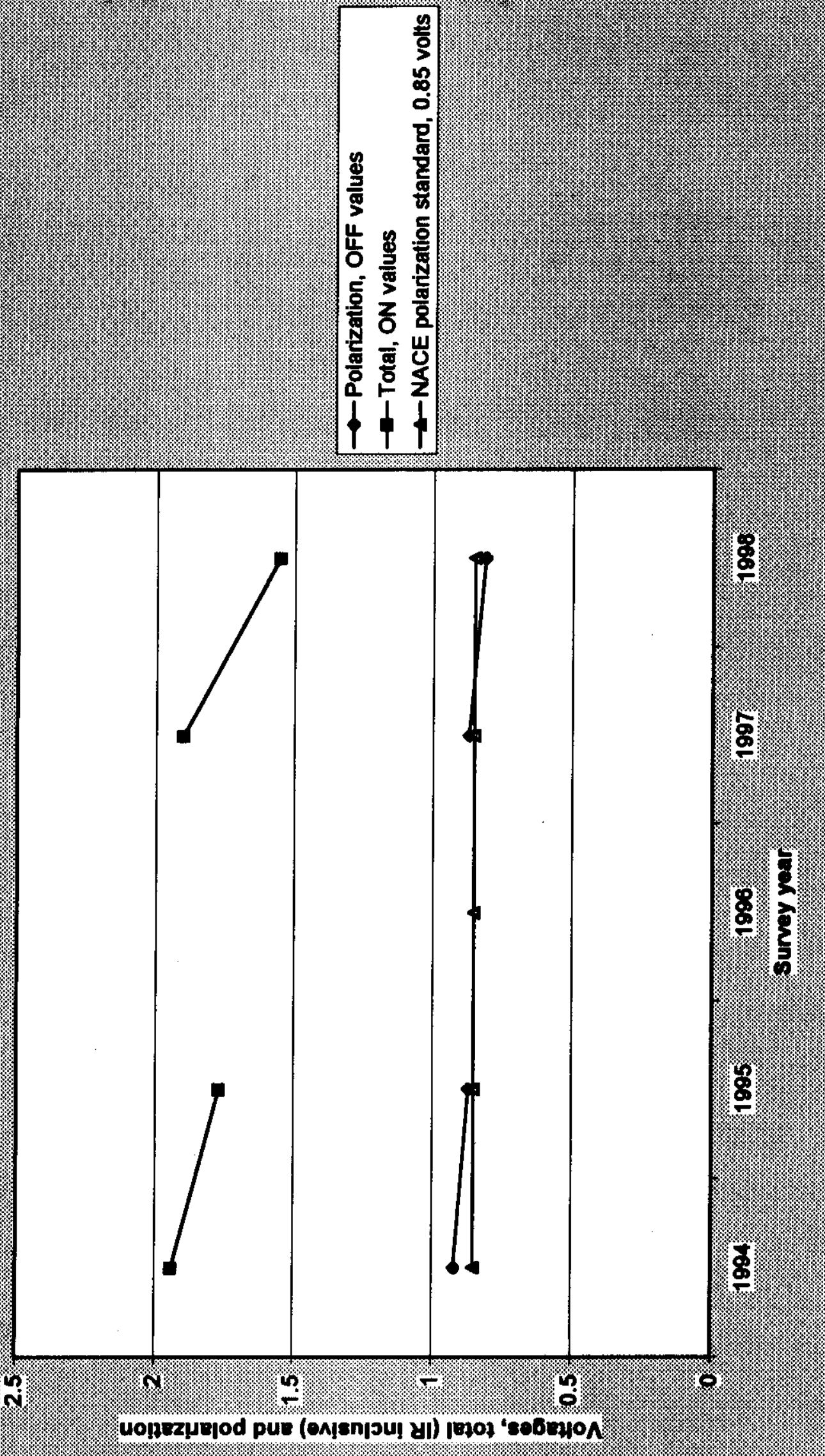

0
5
0
0
8
8
8 
总

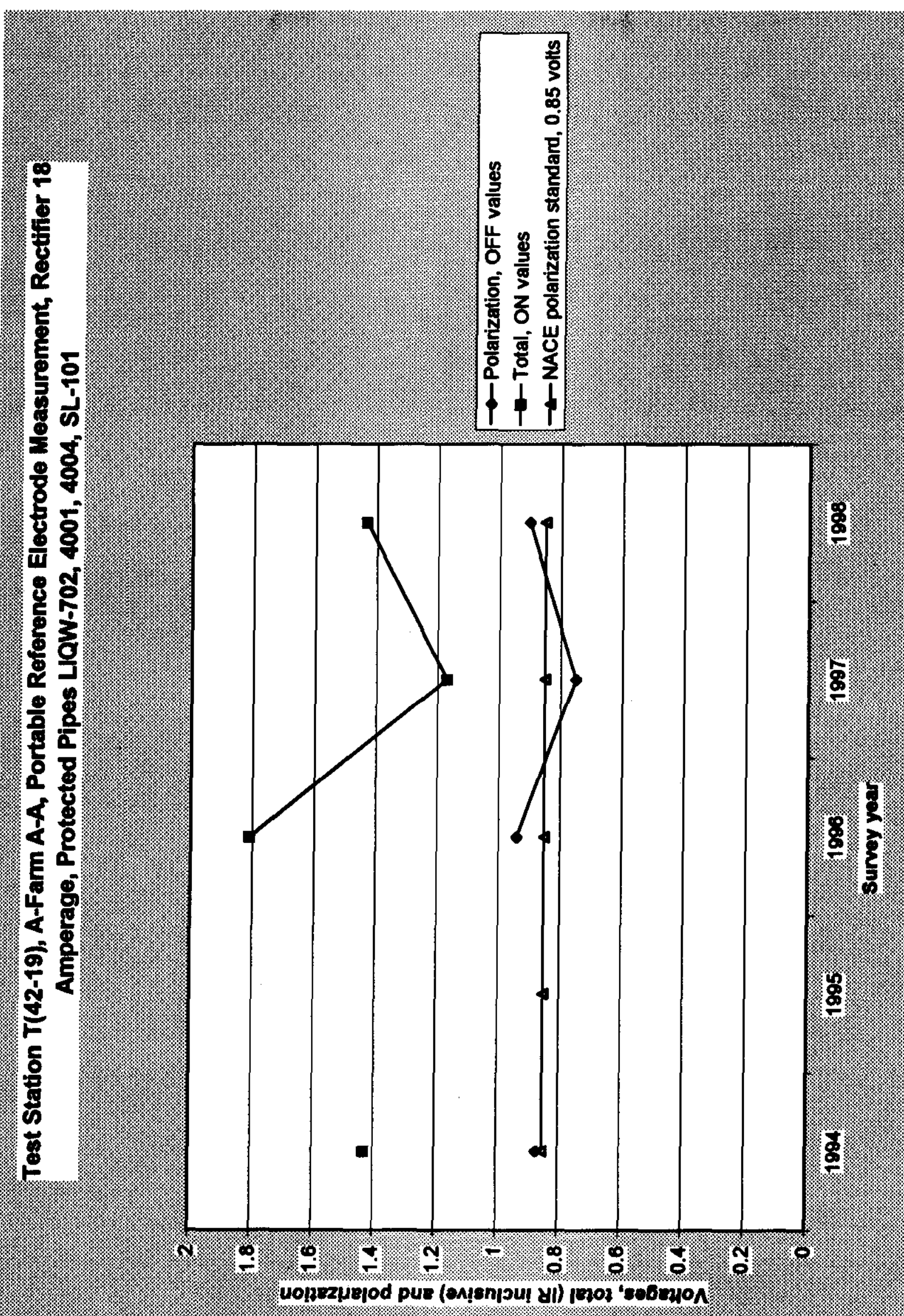

0
0
0
0
0
8
0
0 


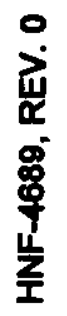
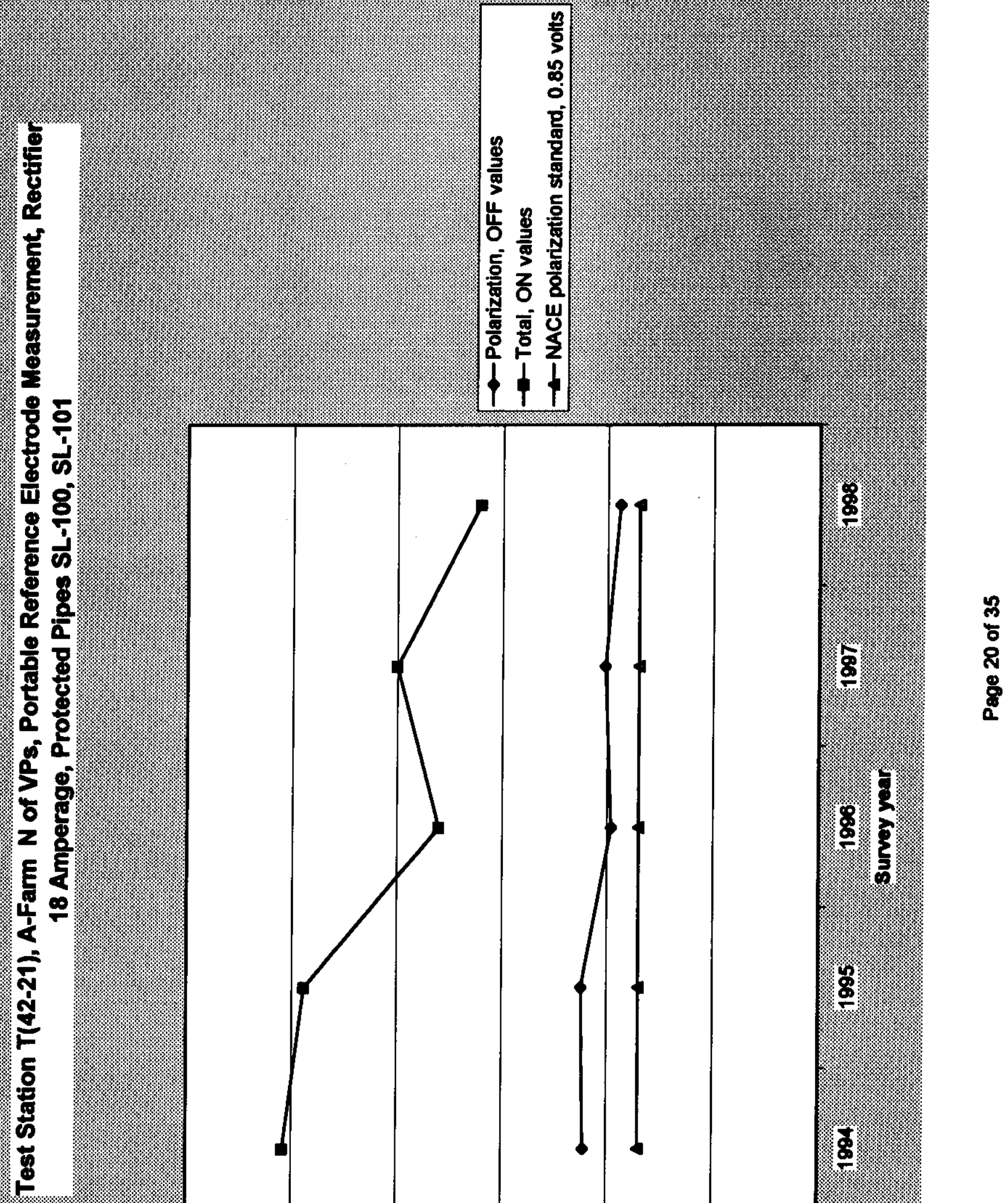
虽
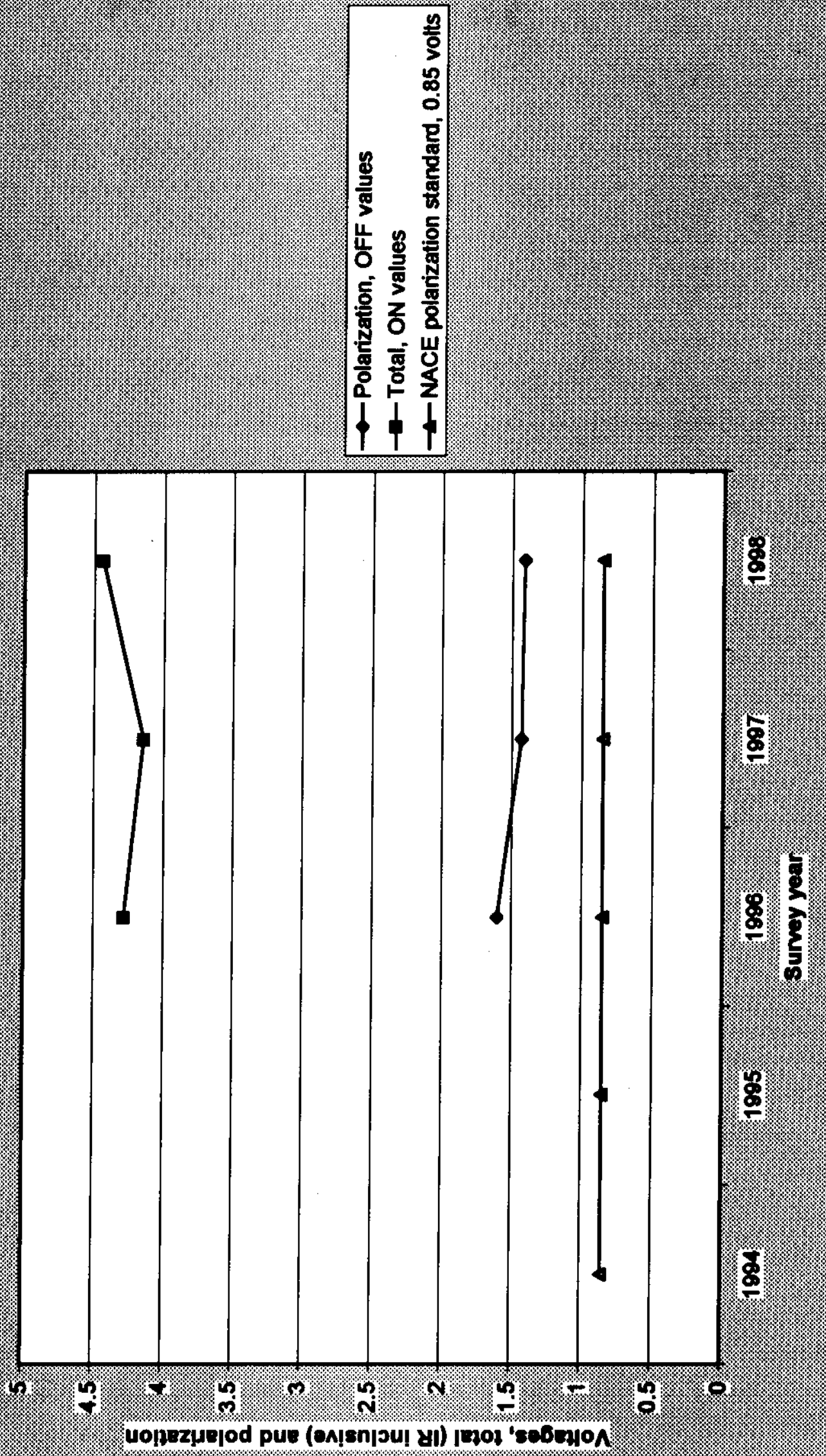


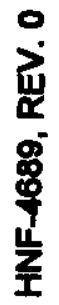
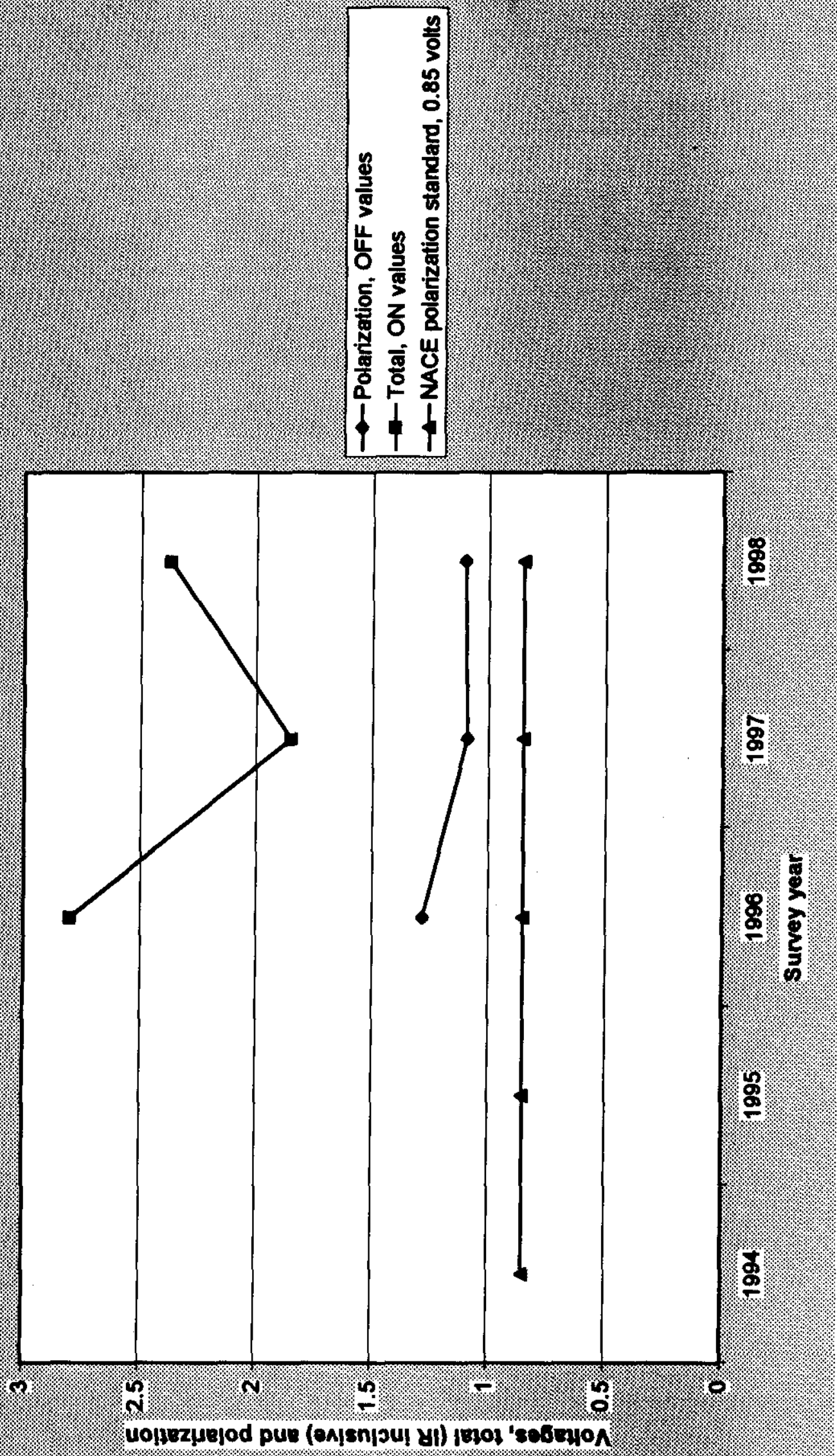

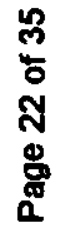


兽

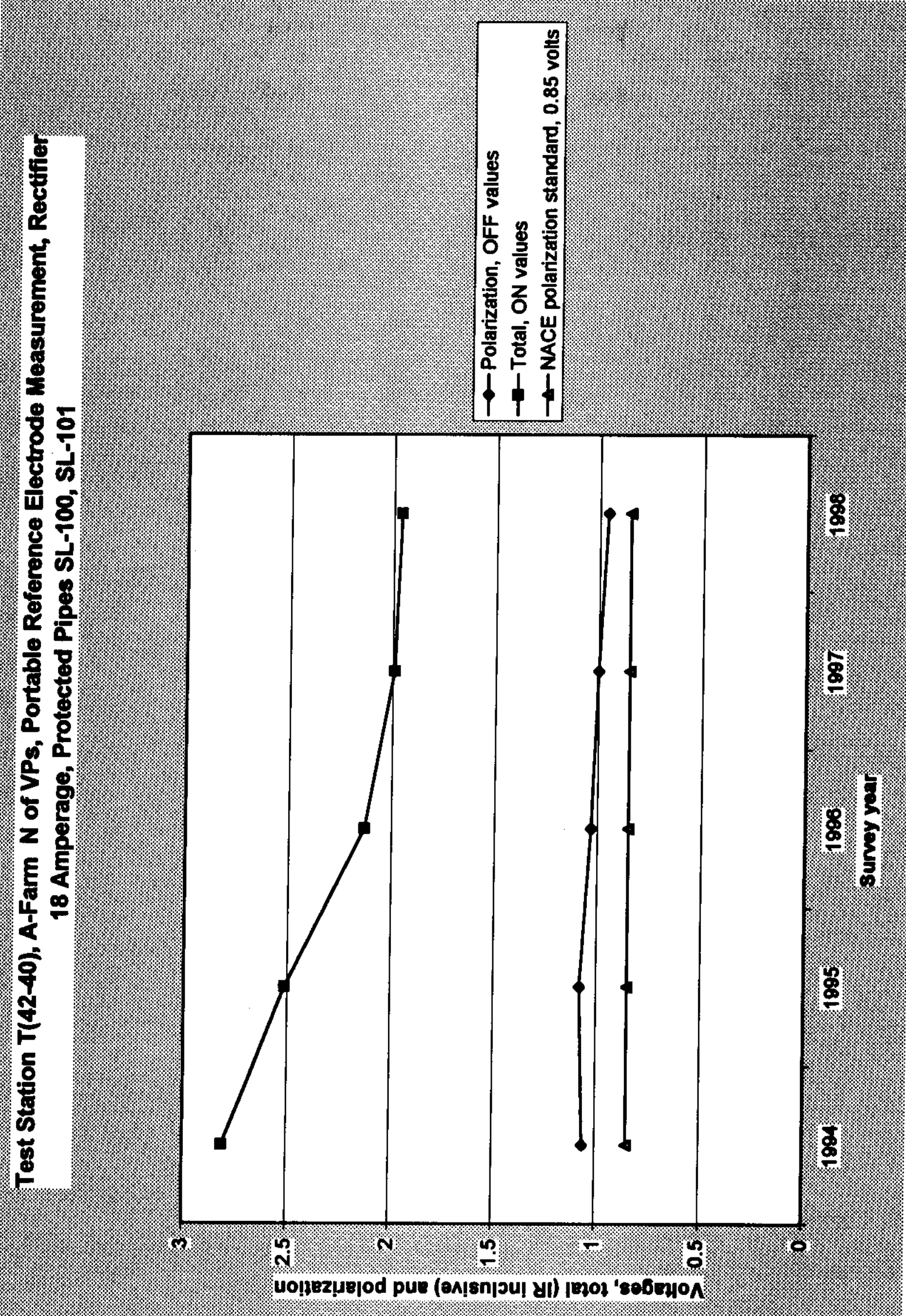

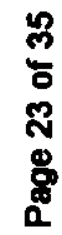




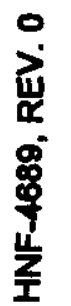

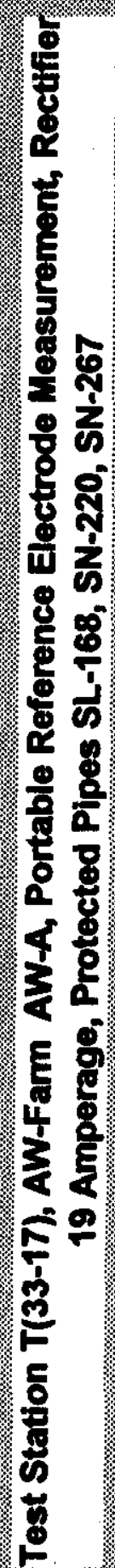

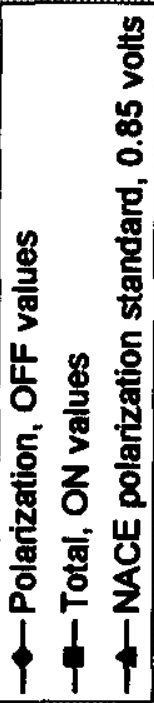

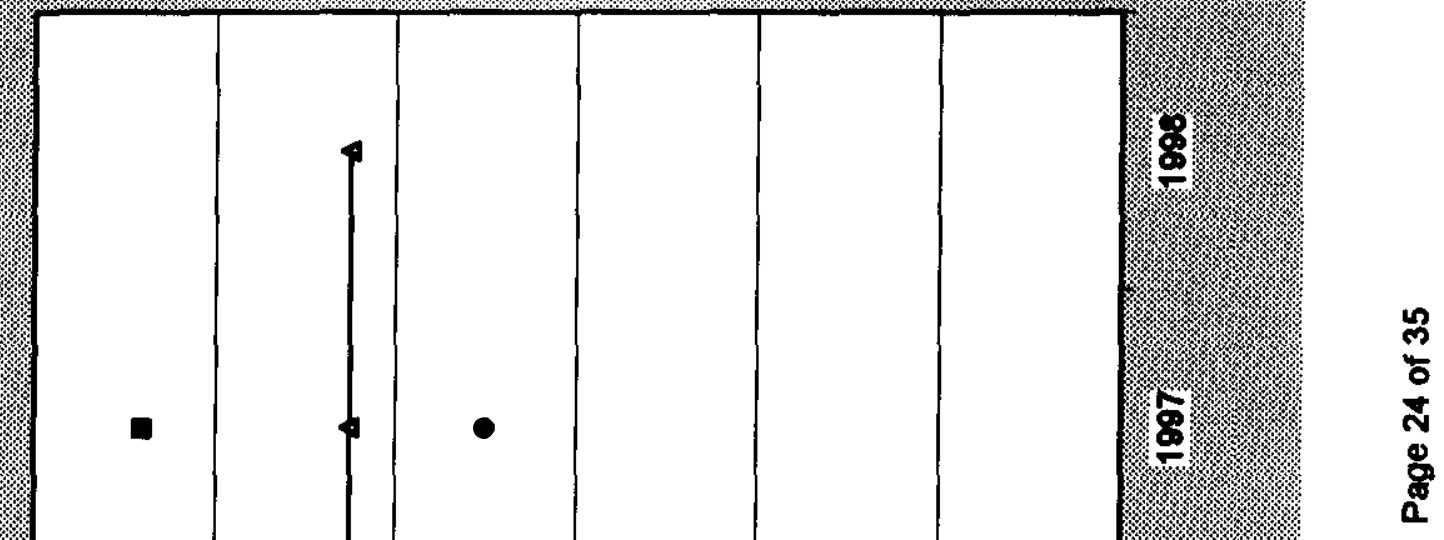




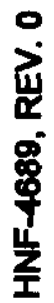
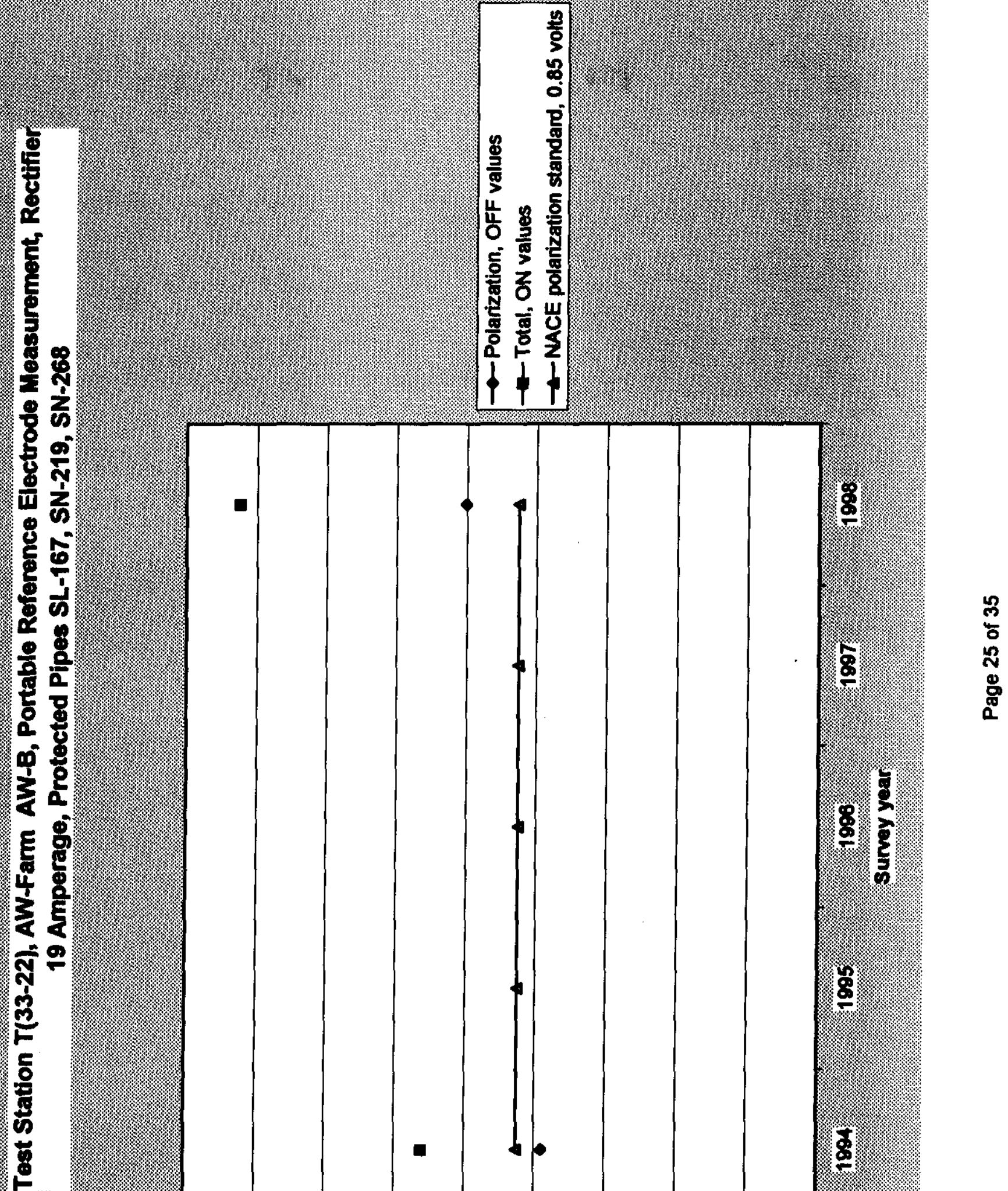


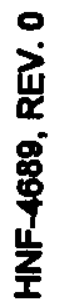
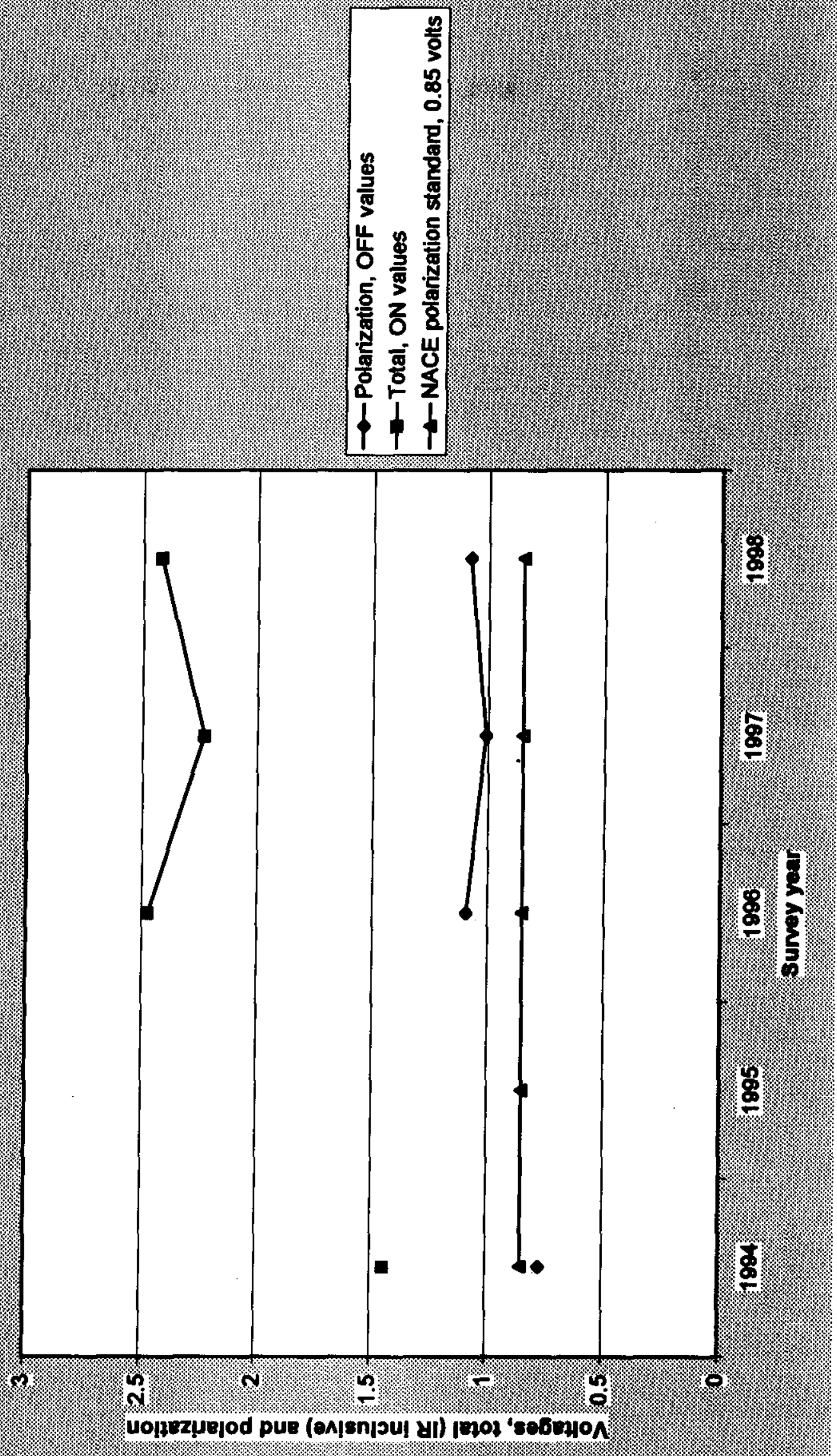

$\mathscr{2}$
0
0
0
0
0
0
0 
章
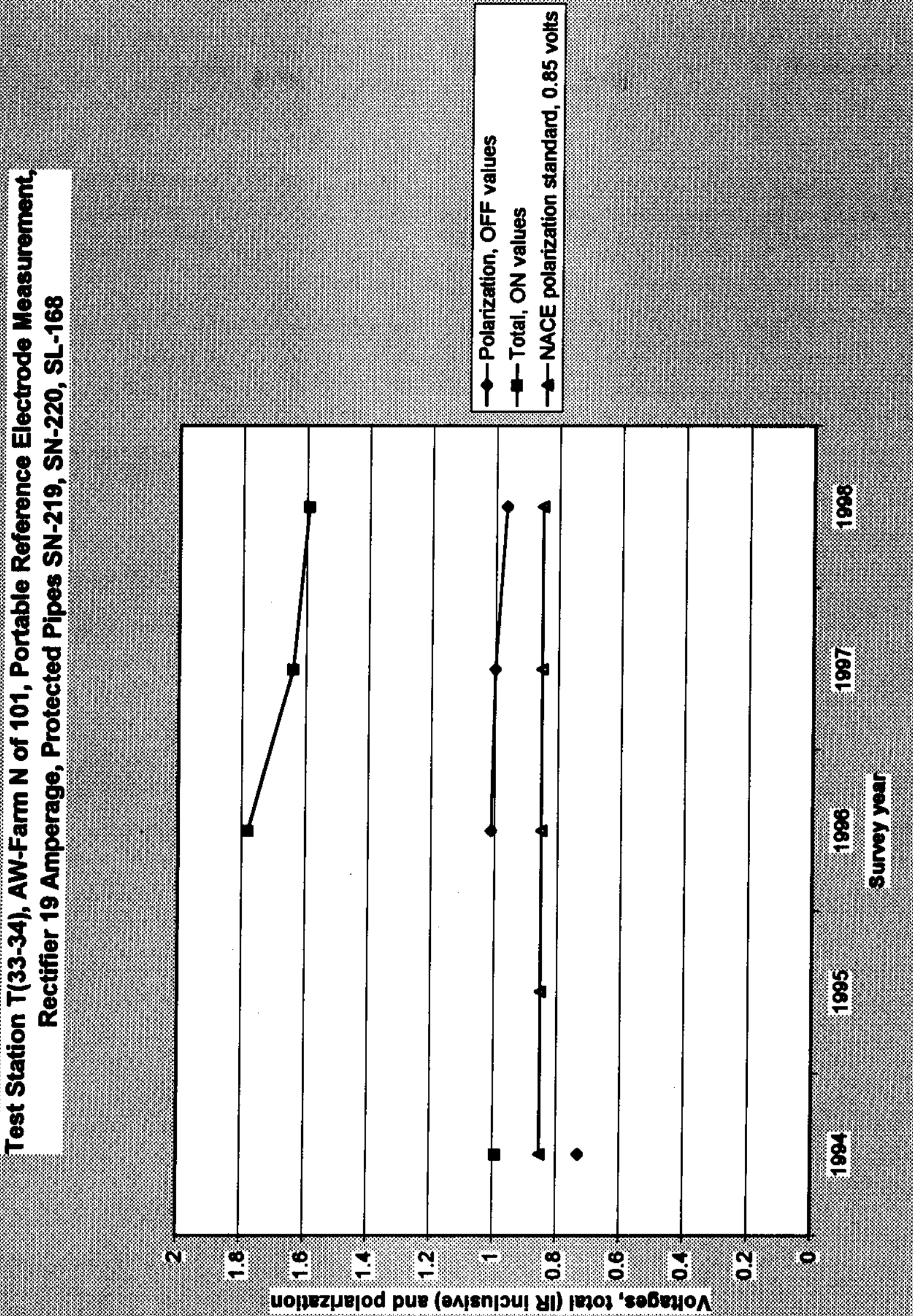

$\frac{8}{5}$
$\frac{5}{1}$
8
8
0 


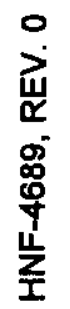
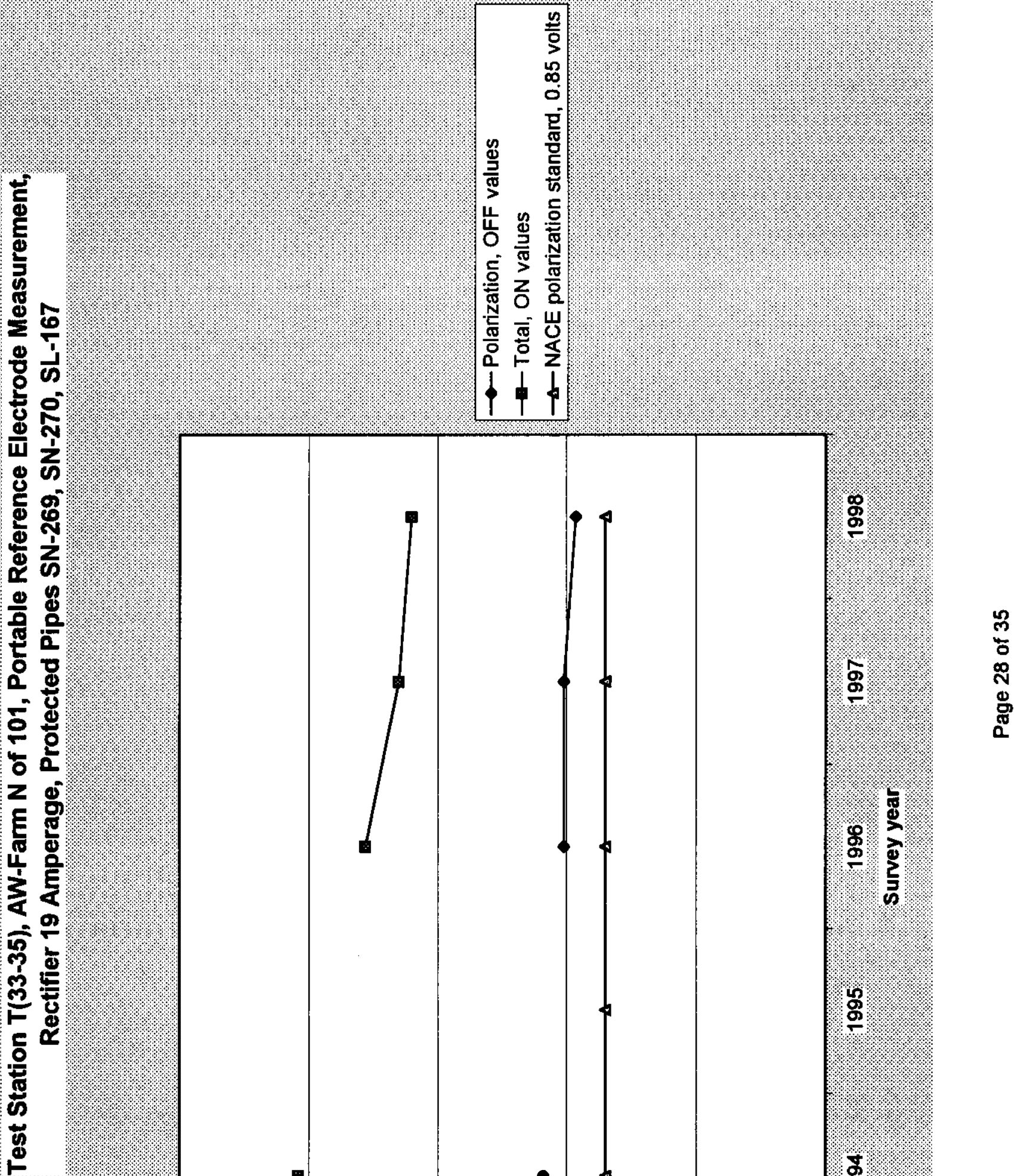
竞

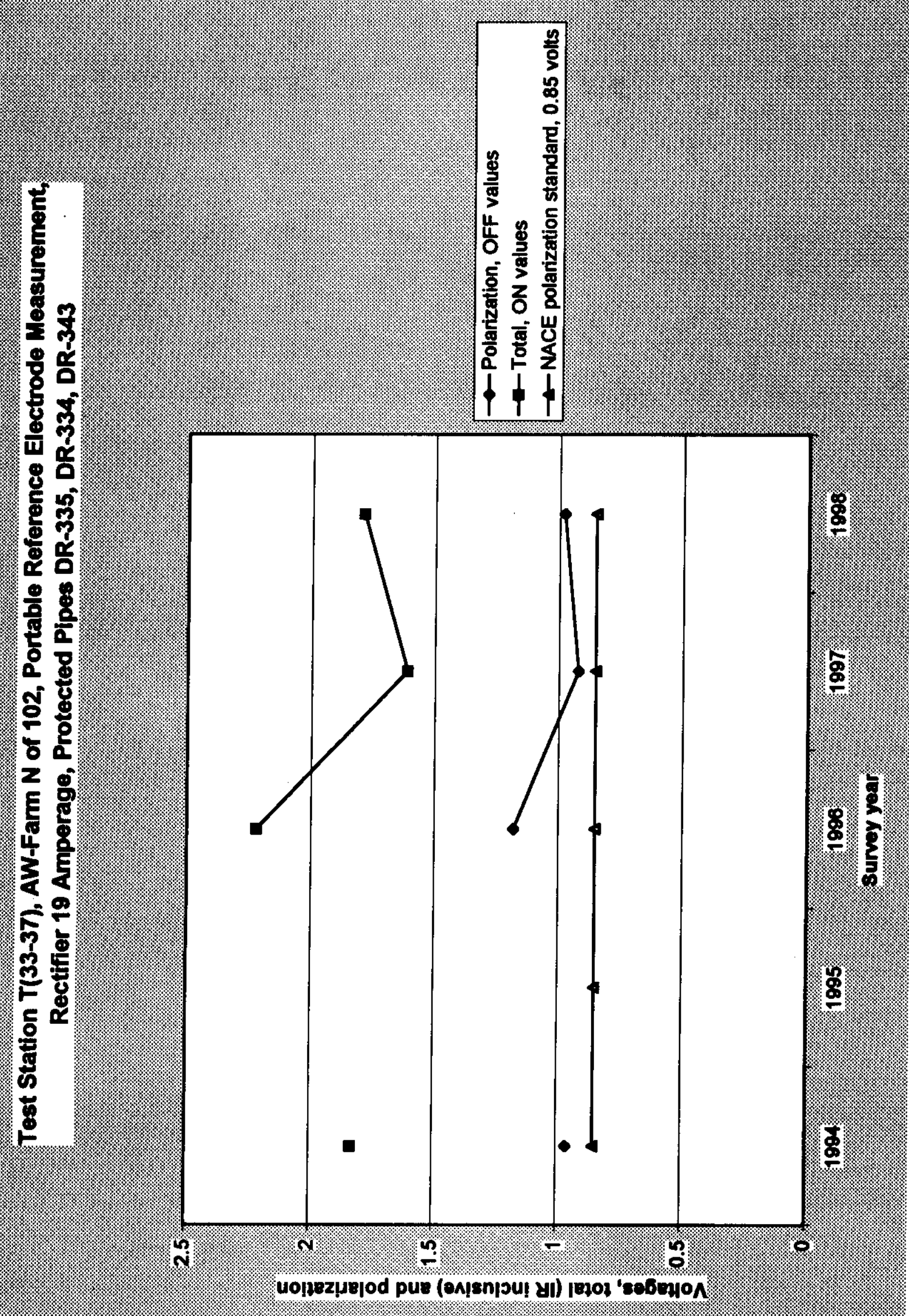

0
8
8
8
8
8
0 


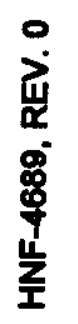
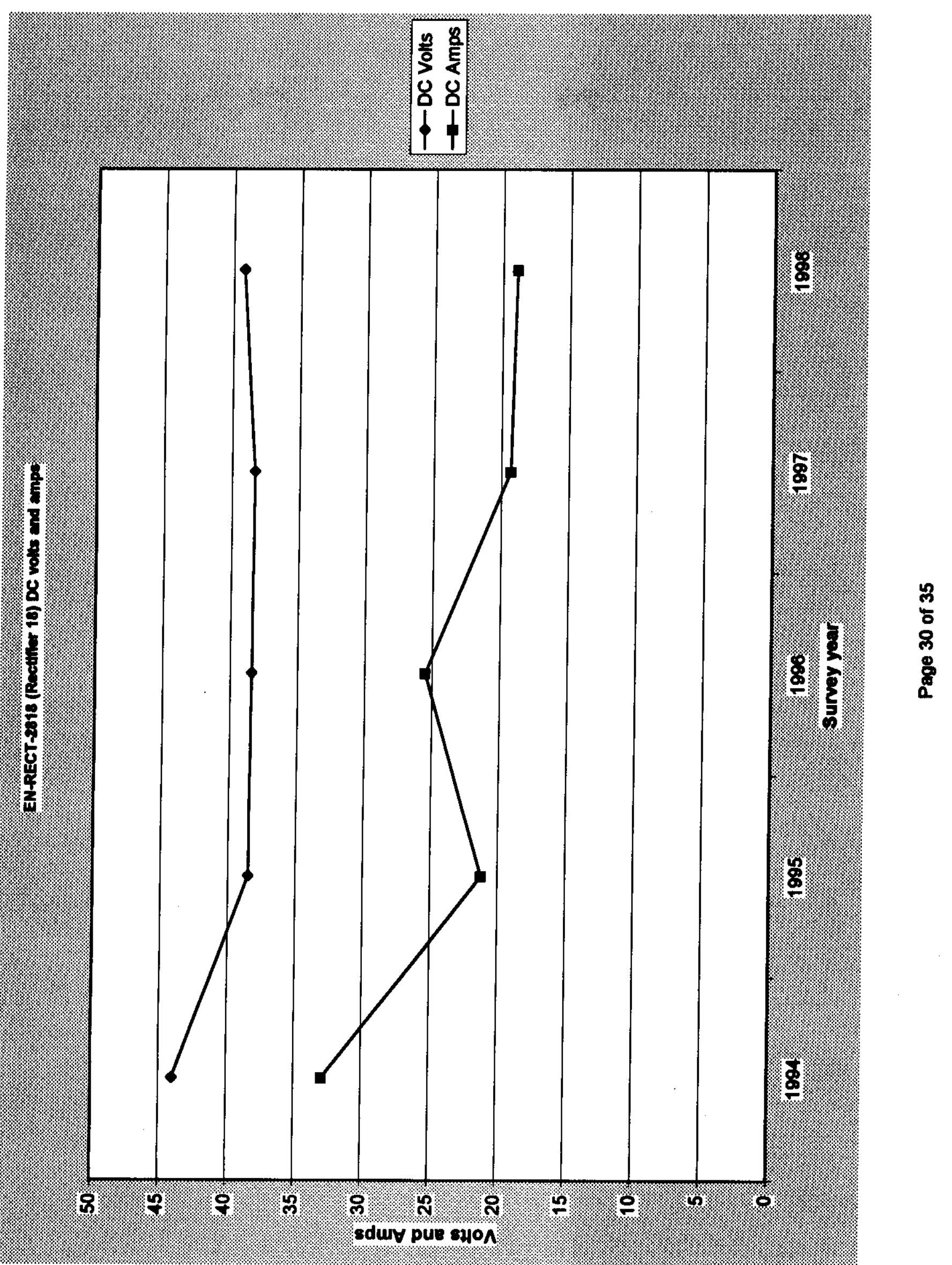


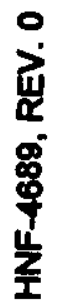
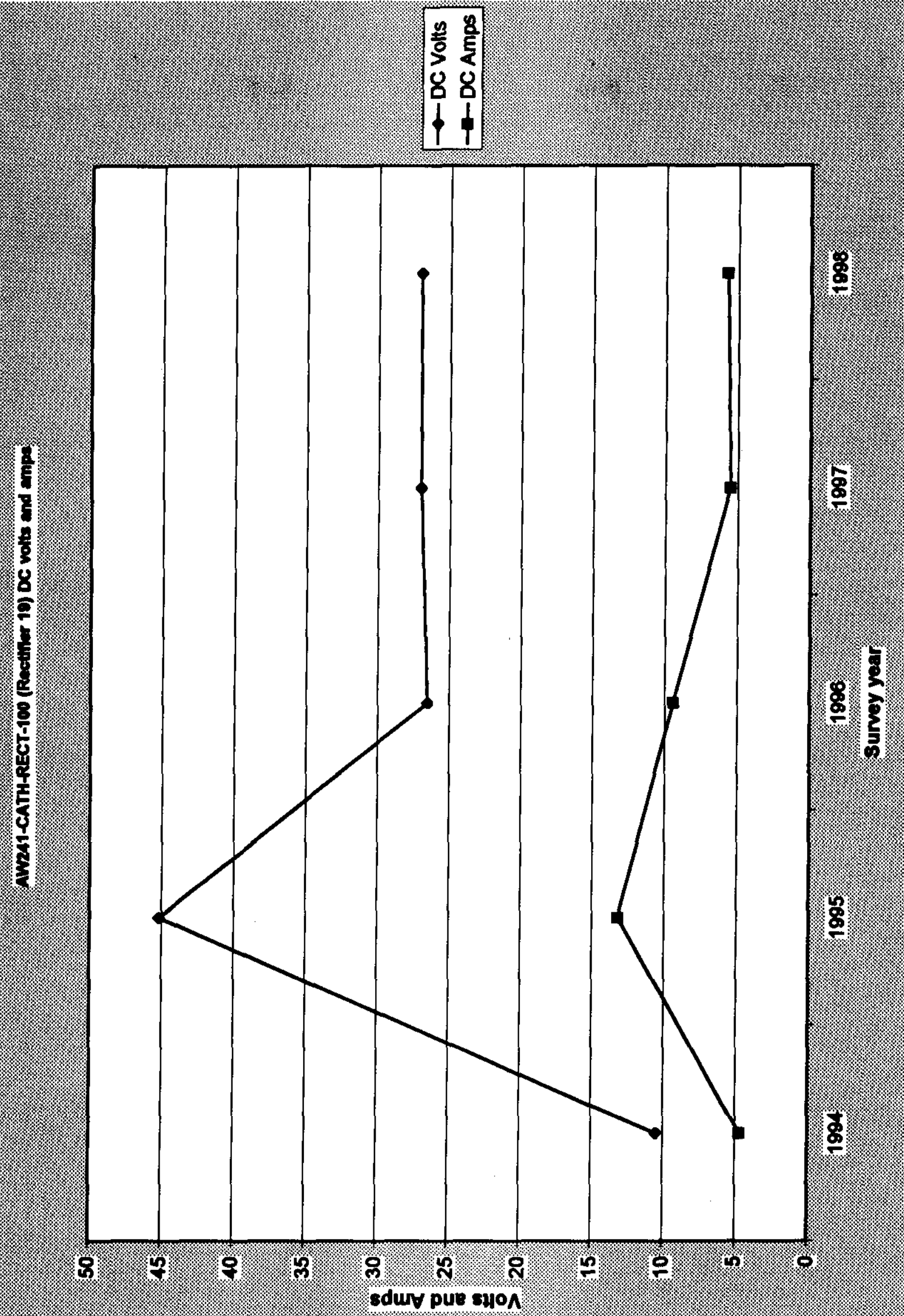


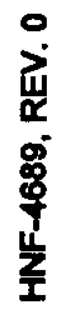
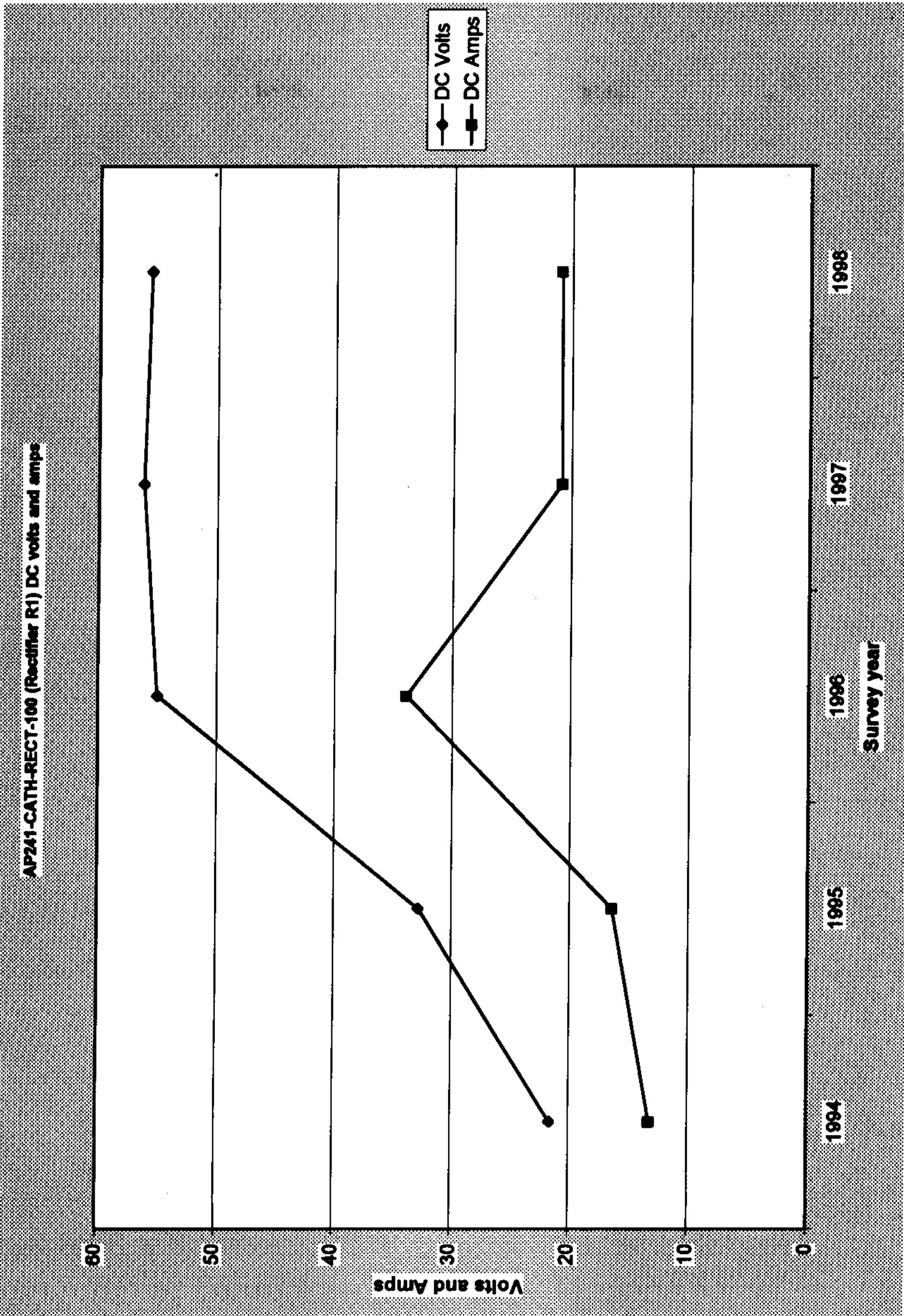
$H N F-4689, R E U . O$

BASELINE, RESURVEY, BIMONTHLY INSPECTION EN-RECT-2818 (RECTIFIER 18)

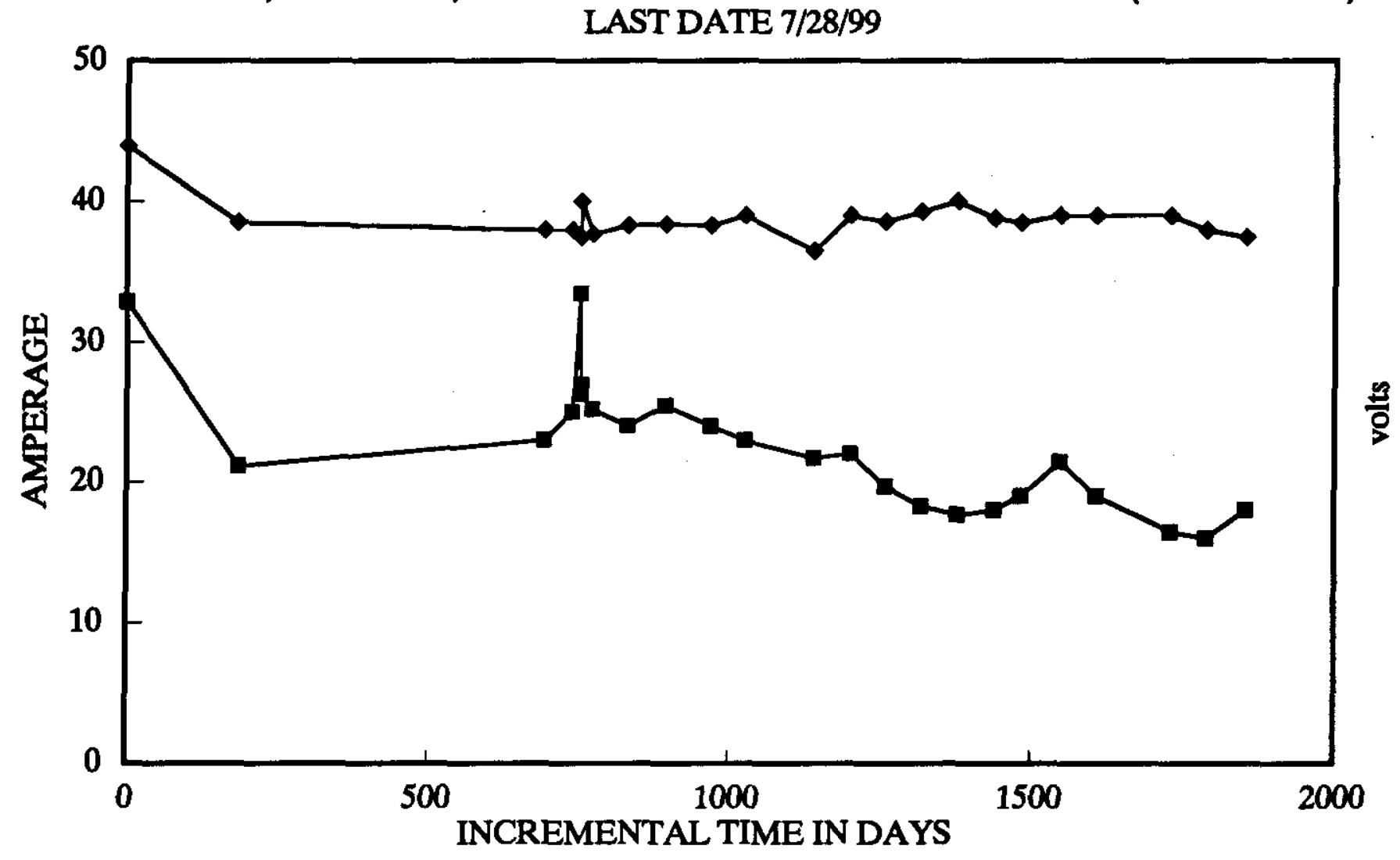

$\rightarrow$ AMPS $\rightarrow$ - VOLTS

PERF-\#18 - NAMEPLATE 120 VOLTS / 40 AMPS

BASELINE DATE - 7/94; RESURVEY DATE - 1/95

Page 33 of 35 
HNF- 4689, REU. O

BASELINE, RESURVEY, BIMONTHLY INSPECTIONS AW241-CATH-RECT-100 (RECT. 19)

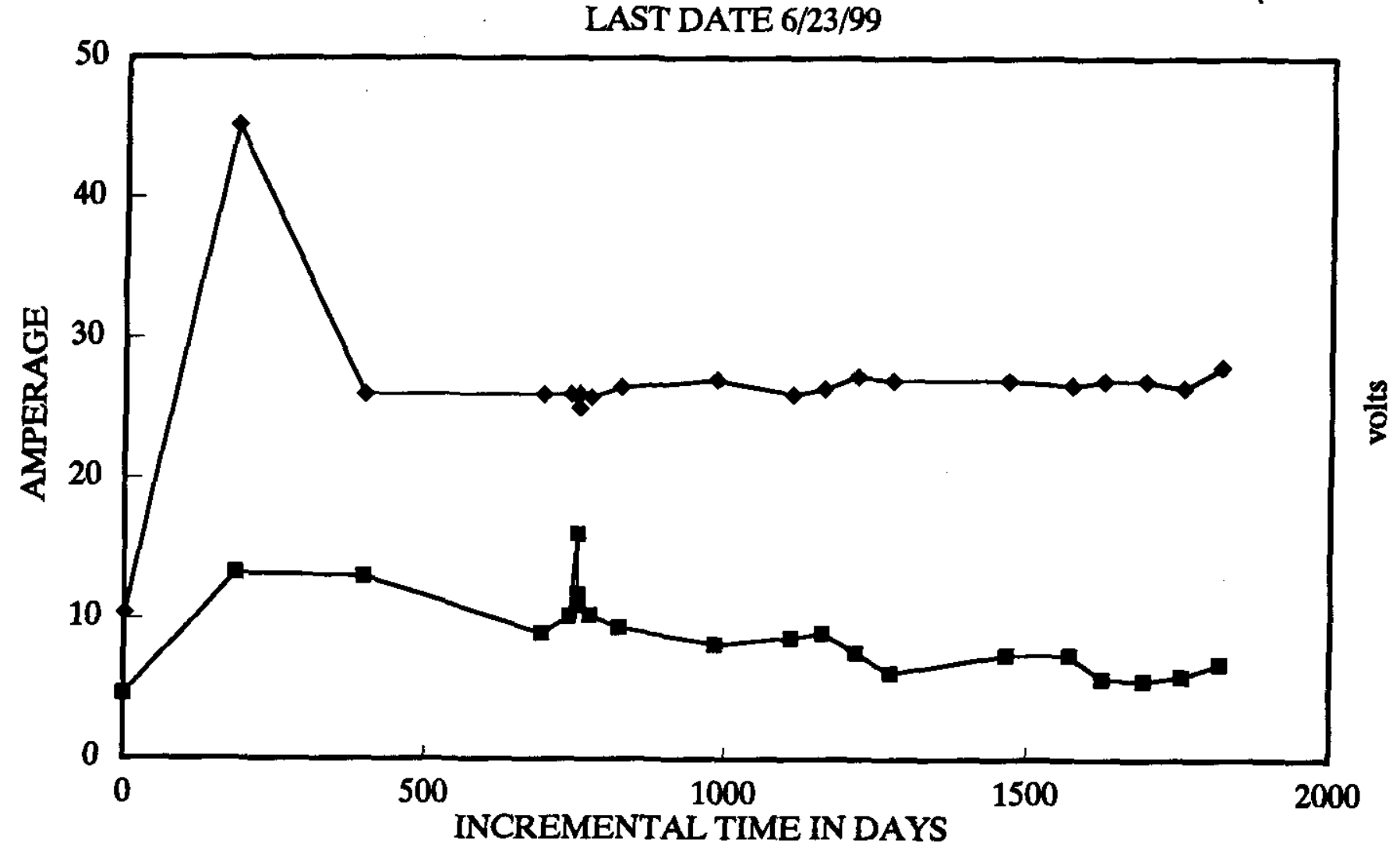

$\rightarrow$ AMPS $\multimap$ VOLTS

PERF - \#19 - NAMEPLATE 40 VOLTS / 12 AMPS

BASELINE DATE - 7/94; RESURVEY DATE - 1/95

Page 34 of 35 
HNF-4689, Reu. O

BASELINE, RESURVEY, BIMONTHLY INSPECTION AP241-CATH-RECT-100 (RECT. R1) LAST DATE 6/23/99

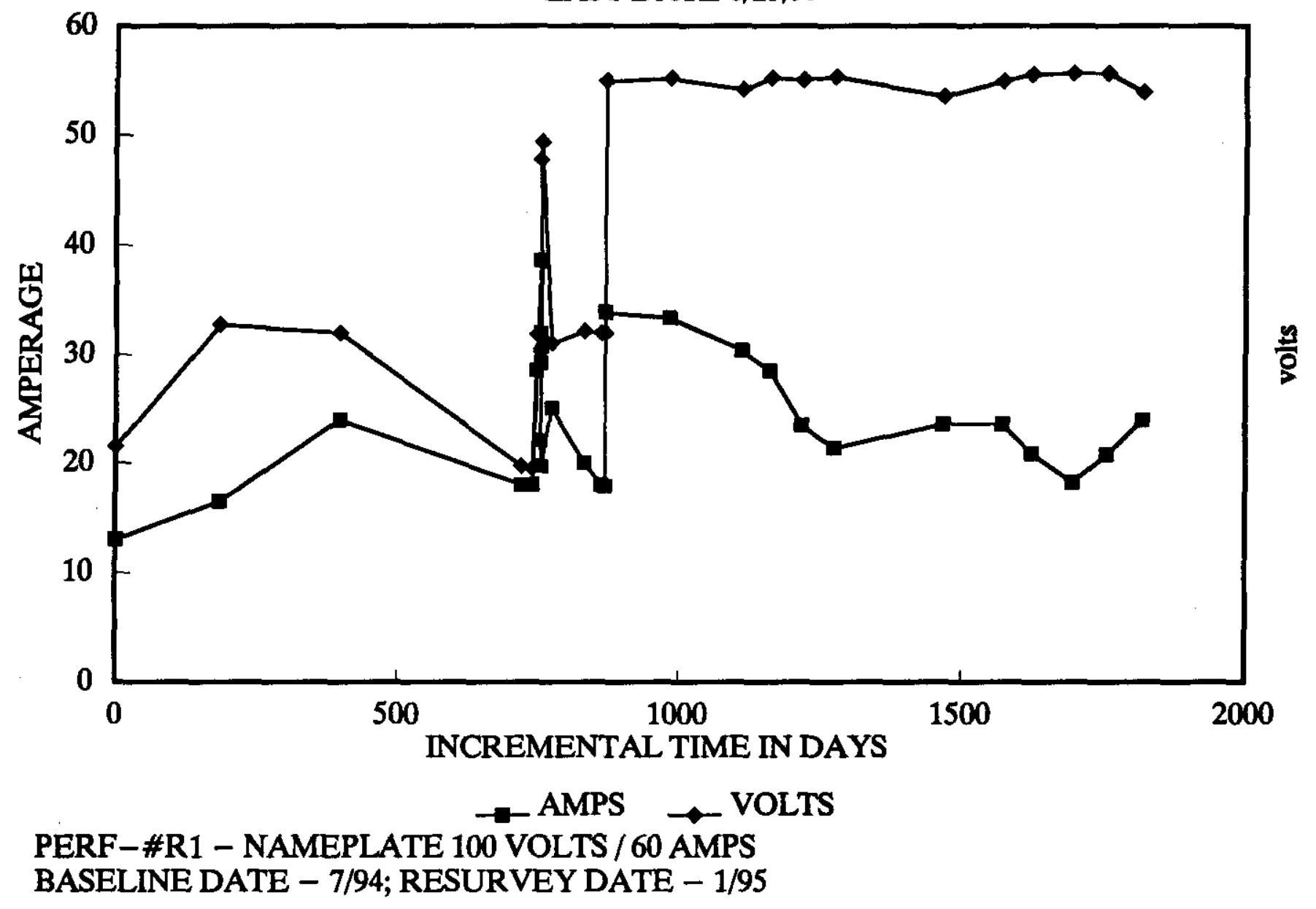

Paye 35 of 35 